

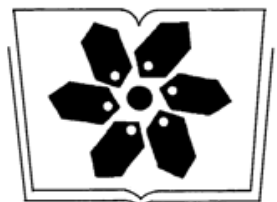

中国科学院科学出版基金资助出版
生 态 学 报

(SHENGTAI XUEBAO)

第 33 卷第 19 期 2013 年 10 月 (半月刊)

中国生态学学会 2013 年学术年会专辑 卷首语

生态系统服务研究文献现状及不同研究方向评述。 马凤娇, 刘金铜, A. Egrinya Eneji (5963) 非人灵长类性打摚行为研究进展 杨斌,王程亮,纪维红,等 (5973) 密度制约效应对啮齿动物繁殖的影响 . 韩群花, 郭 聪, 张美文 (5981) 食物链长度远因与近因研究进展综述 王玉玉,徐军,雷光春 (5990) $\mathrm{AM}$ 真菌在植物病虫害生物防治中的作用机制 罗巧玉，王晓娟，李媛媛，等 (5997) 保护性耕作对农田碳、氮效应的影响研究进展 . 薛建福, 赵 荃金, Shadrack Batsile Dikgwatlhe, 等 (6006) 圈养大熊猫野化培训期的生境选择特征 张明春,黄炎,李德生,等 (6014) 利用红外照相技术分析野生白冠长尾雉活动节律及时间分配 赵玉泽, 王志臣,徐基良,等 (6021) 风速和持续时间对树麻雀能量收支的影响 杨志宏, 吴庆明, 董海燕, 等 (6028) 白马雪山自然保护区灰头小舀鼠的巢址特征 李艳红, 关进科,黎大勇,等 (6035) 生境片段化对千岛湖岛屿上黄足厚结猛蚁遗传多样性的影响 罗媛媛, 刘金亮, 黄杰灵, 等 (6041) 基于 $28 \mathrm{~S}$, COI 和 Cytb 基因序列的薜荔和爱玉子传粉小蜂分子遗传关系研究

吴文珊, 陈友铃, 孙伶俐, 等 (6049) 高榕榕果内 Eupristina 属两种榕小蜂的遗传进化关系 陈友铃, 孙伶例, 武蕾蕾, 等 $(6058)$ 镉胁迫下杞柳对金属元素的吸收及其根系形态构型特征 王树风, 施翔, 孙海菁, 等 (6065) 邻苯二甲酸对萝卜种子萌发、幼苗叶片膜脂过氧化及渗透调节物质的影响

杨延杰, 王晓伟, 赵 康, 等 (6074)

极端干旱区多枝柽柳幼苗对人工水分干扰的形态及生理响应 马晓东, 王明慧, 李卫红, 等 (6081) 贝壳砂生境酸柬叶片光合生理参数的水分响应特征..... 王荣荣,夏江宝,杨吉华,等 (6088) 陶粒覆盖对土壤水分、植物光合作用及生长状况的影响..... 谭雪红, 郭小平, 赵廷宁 (6097) 不同林龄短枝木麻黄小枝单宁含量及养分再吸收动态..... 叶功富, 张尚炬, 张立华,等 (6107)

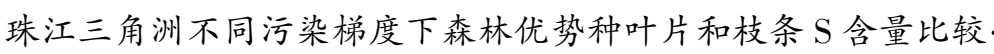
裴男才, 陈步峰, 邹志谨, 等 (6114) $\mathrm{AM}$ 真菌和磷对小马安羊蹄甲幼苗生长的影响 宋成军,曲来叶,马克明, 等 (6121) 盐氮处理下盐地碱蓬种子成熟过程中的离子积累和种子萌发特性............... 周家超,付婷婷, 赵维维,等 (6129) $\mathrm{CO}_{2}$ 浓度升高条件下内生真菌感染对宿主植物的生理生态影响 师志冰, 周 勇, 李 夏, 等 $(6135)$ 预处理方式对香蒲和芦苇种子萌发的影响 孟 焕,王雪宏,佟守正,等 (6142) 镉在土壤-金丝垂柳系统中的迁移特征 雯, 魏 虹, 孙晓灿, 等 (6147) 马尾松人工林近自然化改造对植物自然更新及物种多样性的影响........ 罗应华,孙冬婧,林建勇,等 (6154) 濒危海草贝克喜盐草的种群动态及土壤种子库 以广西珍珠湾为例……

邱广龙,范航清,李宗善,等 (6163)

毛乌素沙地南缘沙丘生物结皮对凝结水形成和蒸发的影响 尹瑞平, 吴永胜, 张 欣, 等 (6173) 塔里木河上游灰胡杨种群生活史特征与空间分布格局…… 韩 路, 席琳乔, 王家强, 等 (6181)

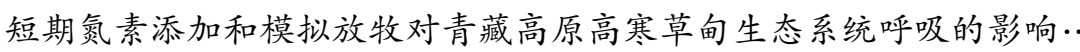
宗宁, 石培礼, 蔣 婧, 等 (6191) 松嫩平原微地形下土壤水盐与植物群落分布的关系 杨 帆,王志春,王云贺,等 (6202) 
广州大夫山雨季林内外空气 TSP 和 $\mathrm{PM}_{2.5}$ 浓度及水溶性离子特征 马鞍列岛岩礁生境鱼类群落结构时空格局…… 黄海细纹狮子鱼种群特征的年际变化. 三种温带森林大型土壤动物群落结构的时空动态 笔管榕榕小蜂的群落结构与物种多样性 海洋生态资本理论框架下的生态系统服务评估 中国地貌区划系统一以自然保护区体系建设为目标..... 生态植被建设对黄土高原农林复合流域景观格局的影响 华北农牧交错带农田-草地景观镶嵌体土壤水分空间异质性 中国北方春小麦生育期变化的区域差异性与气候适应性 中国南方喀斯特石漠化演替过程中土壤理化性质的响应 气候变化对东北沼泽湿地潜在分布的影响…… 内蒙古不同类型草地土壤氮矿化及其温度敏感性 黑河中游荒漠绿洲区土地利用的土壤养分效应 成都平原北部水稻土重金属含量状况及其潜在生态风险评价 大西洋中部延绳钓黄鯺金枪鱼渔场时空分布与温跃层的关系

夏季台湾海峡南部海域上层水体的生物固氮作用 北长山岛森林乔木层碳储量及其影响因子

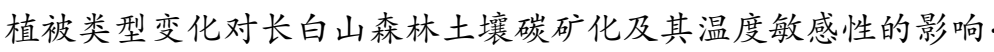
油松遗传结构与地理阻隔因素的相关性 ... 基于辅助环境变量的土壤有机碳空间插值 以黄土丘陵区小流域为例
肖以华, 李昫, 旷远文, 等 (6209) 汪振华, 赵 静, 王 凯, 等 (6218) 陈云龙, 单秀娟, 周志鹏, 等 (6227) . 李 娜, 张雪萍, 张利敏 (6236) 陈友铃, 陈晓倩, 吴文珊, 等 (6246) 陈 尚, 任大川, 夏 涛, 等 (6254) . 郭子良, 崔国发( 6264) 易扬, 信忠保, 覃云斌, 等 (6277) 王红梅, 王仲良, 王 壁, 等 (6287) 俄有浩, 霍治国, 马玉平, 等 (6295) ... 盛茂银, 刘洋, 熊康宁 (6303) 贺伟, 布仁仓, 刘宏娟, 等 (6314) 朱剑兴, 王秋风, 何念鹏, 等 (6320) 马志敏, 吕一河, 孙飞翔, 等 (6328) 秦鱼生, 喻华, 冯文强, 等 (6335) 杨胜龙, 马军杰, 张禹, 等 (6345) 林 峰, 陈 敏, 杨伟锋, 等 (6354) 石洪华, 王晓丽, 王 嫒, 等 (6363) 王丹, 吕瑜良, 徐 丽, 等 (6373) 孟翔翔, 狄晓艳, 王孟本, 等 (6382)

文 雯, 周宝同, 汪亚峰, 等 (6389)

基于生命周期视角的产业资源生态管理效益分析一以虚拟共生网络系统为例

施晓清,李笑诺,杨建新 (6398)

生态脆弱区贫困与生态环境的博弯分析 祁新华, 叶士琳, 程 暗, 等 (6411)

“世博”背景下上海经济与环境的耦合演化 倪 尧, 岳文泽, 张云堂, 等 $(6418)$

期刊基本参数: CN 11-2031/Q * $1981 * \mathrm{~m} * 16 * 464 * \mathrm{zh} * \mathrm{P} * ¥ 90.00 * 1510 * 55 * 2013-10$

封面图说: 毛乌素沙地南缘沙丘的生物结皮一一生物土壤结皮广泛分布于干旱和半干旱区, 它的形成和发育对荒漠生态系统 生态修复过程产生重要的影响。组成生物结皮的藻类、苔藓和地衣是常见的先锋植物, 它们不仅能在严重干旱缺 水、营养贫㾑恶劣的环境中生长、繁殖, 并且能通过其代谢方式影响并改变环境。其中一个重要的特点是, 生物结皮 表面的凝结水显著大于裸沙。研究表明, 凝结水是除降雨之外最重要的水分来源之一, 在水分极度匮乏的荒漠生态 系统, 它对荒漠生态系统结构、功能和过程的维持产生着重要的影响。

彩图及图说提供: 陈建伟教授 北京林业大学 E-mail: cites.chenjw@163.com 
秦鱼生,喻华,冯文强,王正银,涂仕华.成都平原北部水稻土重金属含量状况及其潜在生态风险评价.生态学报,2013,33(19):6335-6344. Qin Y S, Yu H, Feng W Q, Wang Z Y, Tu S H.Assessment on heavy metal pollution status in paddy soils in the northern Chengdu Plain and their potential ecological risk.Acta Ecologica Sinica, 2013,33(19):6335-6344.

\title{
成都平原北部水稻土重金属含量状况 及其潜在生态风险评价
}

\author{
秦鱼生 ${ }^{1,2}$, 喻 华 ${ }^{2}$, 冯文强 ${ }^{2}$, 王正银 ${ }^{1}$, 涂仕华 ${ }^{2}$ * \\ ( 1 . 西南大学资源环境学院, 北碚 $400716 ; 2$. 四川省农业科学院土壤肥料研究所,成都 610066 )
}

\begin{abstract}
摘要:为了解成都平原水稻土重金属含量状况和潜在的生态风险,选取成都平原北部水稻土典型区域为研究对象,采集了 158 个表层土壤样品,分析了土壤中 $\mathrm{pH}$ 值和 $\mathrm{Cd} 、 \mathrm{Cu} 、 \mathrm{As} 、 \mathrm{Hg} 、 \mathrm{~Pb} 、 \mathrm{Cr} 、 \mathrm{Ni} 7$ 种重金属元素含量, 以 20 世纪 80 年代测定的成都平原土壤 重金属元素背景值为评价标准,采用 Hakanson 潜在生态危害指数法对研究区域的重金属潜在生态风险进行了评价。结果表 明:研究区域水稻土 $\mathrm{Cd} 、 \mathrm{Hg} 、 \mathrm{Ni} 、 \mathrm{Cu} 、 \mathrm{~Pb} 、 \mathrm{Cr}$ 和 $\mathrm{As}$ 平均含量分别为 $0.709 、 0.187 、 32.08 、 34.12 、 31.52 、 82.13 \mathrm{mg} / \mathrm{kg}$ 和 $7.25 \mathrm{mg} / \mathrm{kg}$; $\mathrm{Cd} 、 \mathrm{Ni} 、 \mathrm{Cu}$ 和 $\mathrm{Hg} 4$ 种重金属超过《土壤环境质量标准》( GB15618-1995) II 级标准值样本比例分别为 87.34\%、8.23\%、3.80\%和 $3.80 \%, \mathrm{Cd}$ 含量超标严重。7 种重金属元素变异系数幅度为 $18.35 \%-49.03 \%$, 由大到小依次为 $\mathrm{Cd} 、 \mathrm{Hg} 、 \mathrm{Cu} 、 \mathrm{As} 、 \mathrm{Ni} 、 \mathrm{Cr} 、 \mathrm{~Pb}$ 。 $75.32 \%$ 的样本达到中度或较强重金属潜在生态风险, 区域整体表现为中度潜在生态风险 $(R I$ 平均值为 198.65$), \mathrm{Cd}$ 和 $\mathrm{Hg}$ 为高 生态风险元素, 对潜在生态风险贡献率分别为 $62.27 \%$ 和 $20.78 \%, \mathrm{As} 、 \mathrm{~Pb} 、 \mathrm{Cu} 、 \mathrm{Ni} 、 \mathrm{Cr}$ 为低生态风险元素; 风险概率图显示城区周 边和绵远河沿线的潜在生态风险等级较高。因此,成都平原水稻土农业生产中应采取一定的措施防控农产品 $\mathrm{Cd}$ 和 $\mathrm{Hg}$ 污染。
\end{abstract}

关键词 : 水稻土; 重金属; 生态风险; 成都平原

\section{Assessment on heavy metal pollution status in paddy soils in the northern Chengdu Plain and their potential ecological risk}

\author{
QIN Yusheng ${ }^{1,2}$, YU Hua ${ }^{2}$, FENG Wenqiang ${ }^{2}$, WANG Zhengyin ${ }^{1}$, TU Shihua ${ }^{2, *}$ \\ 1 College of Resources and Environment, Southwest University, Chongqing 400716, China \\ 2 Soil and Fertilizer Institute, Sichuan Academy of Agricultural Sciences, Chengdu 610066, China
}

\begin{abstract}
Soil heavy metal pollution has received wide concern due to its widespread and highly toxic nature in environment. Accumulation of heavy metals in agricultural soils tends to elevate crop uptake and finally harm human health through food chains. In order to determine heavy metal pollution status in paddy soils in Chengdu Plain and to assess their potential ecological risk, 158 topsoil samples were collected from the study area, a county typical of paddy rice production with potential pollution of soil heavy metals, to analyze concentrations of seven heavy metals $(\mathrm{Cd}, \mathrm{Hg}, \mathrm{Ni}, \mathrm{Cu}, \mathrm{Pb}, \mathrm{Cr}$ and As ) and $\mathrm{pH}$ in the soils. The background values of the soil heavy metals in Chengdu Plain measured in 1980's were used as references and the Hakanson potential ecological risk index method was adopted in the assessment. The results showed that the average concentrations of $\mathrm{Cd}, \mathrm{Hg}, \mathrm{Ni}, \mathrm{Cu}, \mathrm{Pb}, \mathrm{Cr}$ and $\mathrm{As}$ were measured as 0.709, 0.187, 32.08, 34.12, 31. 52, 82.13 and $7.25 \mathrm{mg} / \mathrm{kg}$, respectively. Compared to level II of the China Soil Environment Quality Standard ( GB 156181995 ), about $87.34 \%, 8.23 \%, 3.80 \%$ and $3.80 \%$ of the total samples were polluted by $\mathrm{Cd}, \mathrm{Ni}, \mathrm{Cu}$ and $\mathrm{Hg}$, respectively. The average concentration of each heavy metal exceeded its soil background values, reflecting an increase in soil heavy metal pollution in Chengdu Plain in recent years. Compared to its background values, Cd had the highest accumulation by $312.2 \%$ while $\mathrm{Hg}$ accumulated the least. Accumulation of the other metals ranged from $5.0 \%$ to $49.03 \%$. The range of
\end{abstract}

基金项目:国家自然科学基金项目(41201295);农业部公益性行业(农业)科研专项(201003016)

收稿日期: 2013-05-20; 修订日期: 2013-07-18

*通讯作者 Corresponding author.E-mail: stu@ ipni.net

http : //www.ecologica.cn 
variation coefficient was $18.35 \%$ to $49.03 \%$ for the seven heavy metals and variation coefficient followed an order of $\mathrm{Cd}>\mathrm{Hg}$ $>\mathrm{Cu}>\mathrm{As}>\mathrm{Ni}>\mathrm{Cr}>\mathrm{Pb}$. Cadmium, $\mathrm{Hg}$ and $\mathrm{Ni}$ showed a logarithmic normal distribution, while $\mathrm{Cu}, \mathrm{Pb}, \mathrm{Cr}$ and $\mathrm{As}$ gave a normal distribution. The Person correlation analysis revealed that significant correlations $(P<0.01)$ were observed among $\mathrm{Cd}, \mathrm{Cu}, \mathrm{Hg}$ and $\mathrm{Ni}$ as well as among $\mathrm{Pb}, \mathrm{Cr}$ and As. The results further suggested that the pollution of $\mathrm{Cd}, \mathrm{Cu}$ and $\mathrm{Ni}$ in the soils might be highly associated with industrial activities, while $\mathrm{Pb}, \mathrm{Cr}$ and $\mathrm{As}$ in the soils could be mainly originated from the soil parent materials. Unlike the other heavy metals, the pollution of $\mathrm{Hg}$ in soils could be most likely due to both the soil parent materials and human activities including industry emissions and loadings from agricultural activities. The ranges of single ecological risk index $\left(E_{r}\right)$ were $28.62-305.8$ for $\mathrm{Cd}, 2.22-11.31$ for $\mathrm{Cu}, 4.58-9.92 \mathrm{for} \mathrm{Pb}, 1.50-$ 3. 59 for $\mathrm{Cr}, 16.57-83.54$ for $\mathrm{Hg}, 3.60-22.38$ for As and 3.97-9.27 for Ni. About 75.32\% of the total samples reached medium or strong level of the potential ecological risk of the heavy metals, but the overall potential ecological risk remained medium (the average $R I=198.65$ ). It was found that $\mathrm{Cd}$ and $\mathrm{Hg}$ contributed most to the ecological risk, accounting for $62.27 \%$ and $20.78 \%$, respectively, and the risks of $\mathrm{As}, \mathrm{Pb}, \mathrm{Cu}, \mathrm{Ni}$ and $\mathrm{Cr}$ were relatively minor. Risk probability map demonstrated that areas around the city and along the Mianyuan River were highly risky. Thus, some counter-measures should be taken to control the pollution of $\mathrm{Cd}$ and $\mathrm{Hg}$ to secure the safe agricultural production in Chengdu Plain.

Key Words : paddy soil ; heavy metal; ecological risk ; Chengdu Plain

随着工农业高速发展和城市化进程加快,工业“三废”排放、矿山开采、城镇生活垃圾处置不当、汽车尾气和农业生产投人 品等带来的土壤污染问题日趋严重,特别是由此带来的土壤重金属污染更是引起了国内外的广泛关注 ${ }^{[1-3]}$ 。据估计,我国受重 金属污染耕地面积已达 2000 多万 $\mathrm{hm}^{2}$, 约占耕地总面积的 $1 / 5$, 每年产出的粮食中约有 1200 万 $\mathrm{t}$ 受重金属污染,合计经济损失 200 多亿元 ${ }^{[4]}$ 。土壤重金属污染具有隐蔽性、滞后性、累积性、复合性、不可逆转性和后果严重性等特点,一旦进人土壤后会导 致农产品重金属累积, 并通过食物链进人人体而危害健康 ${ }^{[5]}$ 。因此,进行土壤重金属污染调查与评价, 掌握土壤环境质量对农 业生产和社会经济的发展都具有十分重要的意义。

成都平原素以 “天府之国” 著称,一直以来都是四川乃至全国粮、油作物的重要生产基地。近年来,随着城市化的快速扩 张, 工矿企业快速发展和农药、化肥等农用物质的大量使用等导致成都平原耕地污染日益加剧。刘红樱等 ${ }^{\left[{ }^{[6]}\right.}$ 研究报道成都平 原 $18.6 \%$ 的区域受到重金属不同程度污染。李冰等 ${ }^{[7]}$ 研究指出成都平原土壤中镉和铅污染相对较严重, 德阳、广汉、新都工业 集中区问题相对突出。刘东盛等 ${ }^{[8]}$ 在成都平原约 6 万 $\mathrm{km}^{2}$ 区域上调查发现表层土壤有较严重的镉、铅、录和砷等重金属超标现 象。然而,已有的研究多采用地质累积指数法、单因子污染指数法、内梅罗综合污染指数法或基于人体健康的风险评价法对成 都平原土壤重金属污染进行评价, 没有考虑生物特性对重金属毒性的响应特征, 缺乏区域内土壤重金属潜在的生态风险评价, 更没有专门针对成都平原水稻土的重金属生态风险评价研究。成都平原水稻土面积占耕地面积的 $84.5 \%$, 是粮食生产的主 体 ${ }^{[9]}$, 因此, 为了确保农产品的安全生产, 对成都平原水稻土重金属污染问题进行深人研究势在必行。Hakanson 潜在生态危害 指数法将重金属生态效应、环境效应与毒理学联系在一起,定量划分重金属的潜在风险等级,既可为改善环境提供依据,还可为 人们的健康生活提供科学参照,已经越来越多的应用于土壤重金属污染评价研究中,姜菲菲等 ${ }^{[10]}$ 运用 Hakanson 法对北京市农 业土壤重金属污染风险等级进行了评价, Wang 等 ${ }^{[11]}$ 和 Sun 等 ${ }^{[12]}$ 都运用 Hakanson 法对城市土壤重金属潜在生态风险进行了研 究。本文在野外调查和室内分析的基础上,采用 Hakanson 潜在生态危害指数法对成都平原水稻土重金属的潜在生态风险进行 综合评价,并运用 GIS 和地统计学方法绘制研究区域重金属元素生态风险概率图, 以期为成都平原水稻土生态风险预警和农产 品安全生产提供科学依据。

\section{1 材料与方法}

\section{1 研究区域概况}

研究区域位于成都平原西北部,介于东经 $103^{\circ} 54^{\prime}$ 至 $104^{\circ} 20^{\prime}$, 北纬 $31^{\circ} 09^{\prime}$ 至 $31^{\circ} 42^{\prime}$ 之间, 海拔高度 $504-4405 \mathrm{~m}$; 幅员面积 约为 $1245.3 \mathrm{~km}^{2}$, 山地占 $52.08 \%$, 平原占 $47.92 \%$, 耕地面积为 $33353 \mathrm{hm}^{2}$, 其中水田面积占耕地总面积的 $90.01 \%$; 主要矿藏有磷 矿、铝土矿、硫铁矿、煤和天然气等。研究区域的土壤类型为灰棕冲积水稻土和灰色冲积水稻土; 属亚热带温湿气候区, 大陆性 季风气候特点显著, 气候温和, 降水充沛, 四季分明, 无霜期长, 年均气温 $15.7{ }^{\circ} \mathrm{C}$, 多年平均 $10{ }^{\circ} \mathrm{C}$ 以上活动积温为 $4887.5{ }^{\circ} \mathrm{C}$, 年 均无霜期为 $285 \mathrm{~d}$, 年均降雨量为 $1040.8 \mathrm{~mm}$, 年均相对湿度为 $81 \%$, 年均蒸发量达 $1100.8 \mathrm{~mm}$, 年均日照时数为 $976.8 \mathrm{~d}$, 全年太 阳辐射值平均为 $335.09 \mathrm{KJ} / \mathrm{cm}^{2}$ 。研究区域的河流属沱江水系,都发源于龙门山脉,主要有绵远河、石亭江等 14 条河流, 由西北 向东南呈树状分布。粮油作物有水稻、小麦、油菜、玉米、大麦、大豆、薯类等,是成都平原粮食生产的重要组成部分。 


\section{2 土壤样品采集与处理}

根据研究区域水稻土的分布情况,在 17 个水稻土主要分布乡镇抽样选取 0-20 cm 耕层土壤样品 158 个(图 1)。采样时用 手持 GPS 仪准确记录样点位置, 在 GPS 定位点田块内采用“S”采取 10-15 个样点的混合样,混合均匀后按四分法获取 0. 5一 $1.0 \mathrm{~kg}$ 样品。采集的样品带回室内在自然状态下风干,去除杂草、植物残体、砾石等,然后用木棒捻细后用玛瑙研钵研磨, 分别 过 20 目和 100 目尼龙篎,分别装瓶,供 $\mathrm{pH}$ 值和重金属全量分析用。

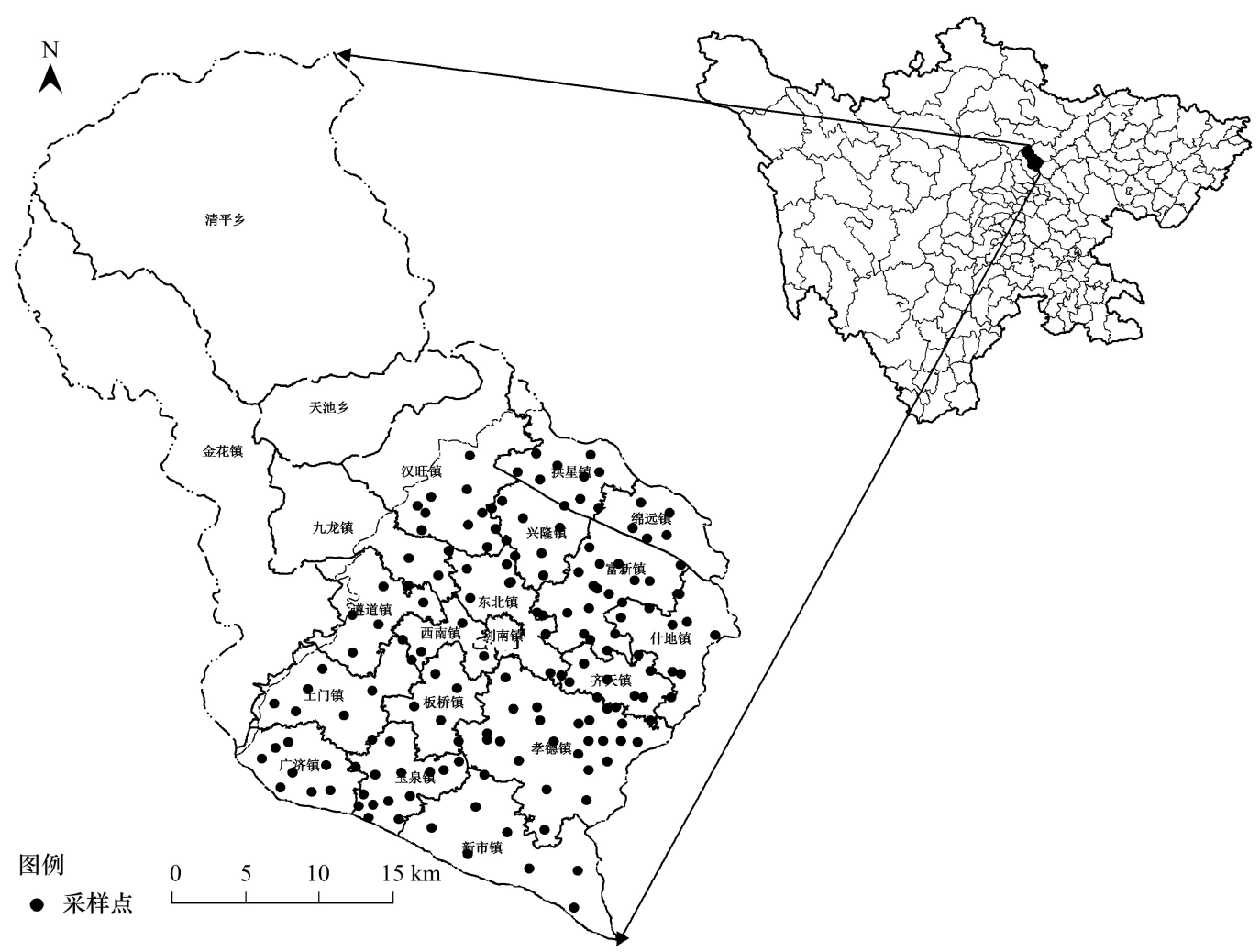

图 1 研究区位置与采样点位分布图

Fig.1 Study area and distribution of the sampling points

\section{3 样品的分析与测定方法}

土壤样品 $\mathrm{pH}$ 值分析参照《土壤农业化学分析方法》 ${ }^{[13]}$, 采用水土比为 $1: 2.5$ 的 $\mathrm{pH}$ 电位法测定。土壤重金属元素 $\mathrm{Cr} 、 \mathrm{Cu} 、$ $\mathrm{Pb} 、 \mathrm{Ni} 、 \mathrm{Cd}$ 全量测定采用土壤过 100 目尼龙篮, 硝酸-高氯酸-氢氟酸三酸消解后, $\mathrm{Cr} 、 \mathrm{Cu} 、 \mathrm{~Pb} 、 \mathrm{Ni}$ 用火焰原子吸收分光光度计测 定, $\mathrm{Cd}$ 用石墨炉原子吸收分光光度计测定; $\mathrm{As}$ 和 $\mathrm{Hg}$ 全量测定采用硝酸-硫酸消解后,用原子苂光光谱仪测定。土壤重金属分 析的质量控制采用 GSS- 14 标准物质进行加标回收, Cr、 Cu、Pb、Ni、Cd、 $\mathrm{Hg}$ 和 As 的回收率分别达 95.4\%-103.2\%、96.6\%一 $102.5 \% 、 95.3 \%-103.7 \% 、 91.8 \%-99.6 \% 、 92.9 \%-105.1 \% 、 93.4 \%-98.3 \%$ 和 $91.1 \%-97.9 \%$ 。

\section{4 数据处理与分析}

本研究的土壤重金属含量描述性统计、Kolmogorov-Smirnov 正态分布检验、相关分析、因子分析等统计采用 SPSS19.0 分析; 相关图件制作在 ArcGIS 10.0 中完成; 在 Excel 2007 中以平均值加减 3 倍标准差的标准对原始数据进行异常值分析,结果显示 全部 158 个样点的分析测试结果都为有效数据,无异常值样点剔除, 异常分析后进行重金属污染评价的数据计算。

1.5 潜在生态风险指数法 (Hakanson 法)

潜在生态风险指数法是由瑞典科学 Hakanson 在评价沉积物的重金属污染时提出 ${ }^{[14]}$, 其计算公式如下:

$$
\begin{gathered}
C_{f}^{i}=\frac{C_{i}}{C_{n}^{i}} \\
C_{d}=\sum_{i=1}^{n} C_{f}^{i} \\
E_{r}^{i}=T_{r}^{i} \times C_{f}^{i} \\
R I=\sum_{i=1}^{n} E_{r}^{i}=\sum_{i=1}^{n}\left(T_{r}^{i} \times C_{f}^{i}\right)
\end{gathered}
$$


式中, $C_{f}^{i}$ 为某重金属的单因子污染指数; $C_{i}$ 为土壤中重金属的实测含量; $C_{n}^{i}$ 为重金属的参比值,一般采用土壤中重金属元素的 背景值, 本研究重金属背景值采用姚延伸测定的成都平原土壤重金属元素背景值 ${ }^{[15]}$, 其中 $\mathrm{Cd}$ 为 $0.172 \mathrm{mg} / \mathrm{kg} 、 \mathrm{Cu}$ 为 $28.1 \mathrm{mg} /$ $\mathrm{kg} 、 \mathrm{~Pb}$ 为 $23.1 \mathrm{mg} / \mathrm{kg} 、 \mathrm{Cr}$ 为 $70.3 \mathrm{mg} / \mathrm{kg} 、 \mathrm{Hg}$ 为 $0.181 \mathrm{mg} / \mathrm{kg} 、 \mathrm{As}$ 为 $6.42 \mathrm{mg} / \mathrm{kg}$ 和 Ni 为 $27.3 \mathrm{mg} / \mathrm{kg} ; C_{d}$ 为多种重金属的污染指数 之和; $E_{r}^{i}$ 为单项重金属潜在生态风险指数; $T_{r}^{i}$ 为单项重金属毒性响应参数; $R I$ 为区域多因子潜在生态风险指数。

重金属毒性响应系数设定参照 Hakanson 和徐争启 ${ }^{[16]}$ 研究结果, 7 种重金属毒性响应系数分别为: $\operatorname{Hg}(40)>\operatorname{Cd}(30)>A s$ $(10)>\mathrm{Cu}(5)=\mathrm{Pb}(5)=\mathrm{Ni}(5)>\operatorname{Cr}(2)$ 。单因子重金属污染指数 $C_{f}^{i}$ 、单因子重金属潜在生态风险指数 $E_{r}^{i}$ 、区域多因子重金属综 合潜在生态风险指数 $R I$ 和污染程度的关系采用张菊等 ${ }^{[17]}$ 划分的潜在生态风险分级标准, 单因子潜在生态风险指数 $40 、 80 、 160$ 和 320 分别为轻度、中度、较强、很强和极强等级的阈值, 区域多因子重金属综合潜在生态风险指数 $150 、 300$ 和 600 分别为轻 度、中度、较强和很强等级的國值。

\section{2 结果与分析}

\section{1 水稻土重金属含量统计特征分析}

研究区域水稻土 158 个样点 7 种重金属含量的描述性统计结果见表 1 , 采用姚延伸报道的成都平原水稻土背景值进行累积 分析,采用《土壤环境质量标准》( GB15618-1995) ${ }^{[18]}$ 中 II 级标准进行污染状况分析。从表 1 可以看到,水稻土不同重金属元 素含量差异较大, $\mathrm{Cd}$ 为 $0.164-1.753 \mathrm{mg} / \mathrm{kg}, \mathrm{Cu}$ 为 $12.50-63.57 \mathrm{mg} / \mathrm{kg}, \mathrm{Pb}$ 为 $21.14-45.81 \mathrm{mg} / \mathrm{kg}, \mathrm{Cr}$ 为 $52.84-126.21 \mathrm{mg} / \mathrm{kg}$, $\mathrm{Hg}$ 为 $0.08-0.38 \mathrm{mg} / \mathrm{kg}, \mathrm{As}$ 为 $2.31-14.37 \mathrm{mg} / \mathrm{kg}$ 和 $\mathrm{Ni}$ 为 $21.42-50.59 \mathrm{mg} / \mathrm{kg}$ 。Cd、Cu、 $\mathrm{Hg}$ 和 $\mathrm{Ni}$ 都有超过土壤环境质量二级标 准的样本分布, $\mathrm{Cd}$ 超标样本比例最大, 达到 $87.34 \%$; Ni、Cu 和 $\mathrm{Hg}$ 超标样本比例分别为 $8.23 \% 、 3.80 \%$ 和 $3.80 \%$, 这说明研究区 域水稻土存在这 4 种重金属污染; 而 $\mathrm{Pb} 、 \mathrm{Cr}$ 和 $\mathrm{As}$ 与土壤环境质量二级标准相差较远, 表明研究区域水稻土尚未受到 $\mathrm{Pb} 、 \mathrm{Cr}$ 和 As 污染。不同 $\mathrm{pH}$ 值范围下的 $\mathrm{Cd} 、 \mathrm{Cu} 、 \mathrm{Hg}$ 和 $\mathrm{Ni}$ 这 4 种元素平均值与土壤环境质量二级标准对比分析来看, $\mathrm{pH}$ 值 $<6.5$ 的土壤样 本 $\mathrm{Cd}$ 平均值超标 1.64 倍, $\mathrm{pH}$ 值介于 6.5-7.5 之间的土壤样本 $\mathrm{Cd}$ 平均值超标 1.68 倍, $\mathrm{pH}$ 值 $>7.5$ 的土壤样本 $\mathrm{Cd}$ 平均值超标 1.12 倍; $\mathrm{Cu} 、 \mathrm{Hg}$ 和 $\mathrm{Ni}$ 的平均值尚未超过土壤环境质量二级标准。

表 1 研究区域土壤重金属描述性统计

Table 1 Summary statistics of heavy metal concentrations in the topsoil in the study area

\begin{tabular}{|c|c|c|c|c|c|c|c|}
\hline $\begin{array}{l}\text { 重金属 } \\
\text { Heavy metal }\end{array}$ & $\begin{array}{c}\mathrm{Cd} \\
/(\mathrm{mg} / \mathrm{kg})\end{array}$ & $\begin{array}{c}\mathrm{Cu} \\
/(\mathrm{mg} / \mathrm{kg})\end{array}$ & $\begin{array}{c}\mathrm{Pb} \\
/(\mathrm{mg} / \mathrm{kg})\end{array}$ & $\begin{array}{c}\mathrm{Cr} \\
/(\mathrm{mg} / \mathrm{kg})\end{array}$ & $\begin{array}{c}\mathrm{Hg} \\
/(\mathrm{mg} / \mathrm{kg})\end{array}$ & $\begin{array}{c}\mathrm{As} \\
/(\mathrm{mg} / \mathrm{kg})\end{array}$ & $\begin{array}{c}\mathrm{Ni} \\
/(\mathrm{mg} / \mathrm{kg})\end{array}$ \\
\hline 平均值 Mean & 0.709 & 34.12 & 31.52 & 82.13 & 0.187 & 7.25 & 32.08 \\
\hline 中值 Median & 0.637 & 32.95 & 30.77 & 80.78 & 0.17 & 7.00 & 30.58 \\
\hline 最小值 Minimum & 0.164 & 12.50 & 21.14 & 52.84 & 0.08 & 2.31 & 21.42 \\
\hline 最大值 Maximum & 1.753 & 63.57 & 45.81 & 126.21 & 0.38 & 14.37 & 50.59 \\
\hline 变异系数 Coefficient of variance/\% & 49.03 & 33.09 & 18.35 & 18.99 & 37.58 & 32.97 & 20.12 \\
\hline 标准差 Standard deviation & 0.348 & 11.29 & 5.78 & 15.59 & 0.07 & 2.39 & 6.45 \\
\hline 背景值 * Background value & 0.172 & 28.1 & 23.1 & 70.3 & 0.181 & 6.42 & 27.3 \\
\hline 最高限值 ${ }^{* *}$ & 0.30 & 50 & 250 & 250 & 0.30 & 30 & 40 \\
\hline \multirow[t]{2}{*}{ Permitted maximum value } & 0.60 & 100 & 300 & 300 & 0.50 & 25 & 50 \\
\hline & 1.00 & 100 & 350 & 350 & 1.00 & 20 & 60 \\
\hline
\end{tabular}

* 成都平原水稻土重金属背景值 ${ }^{[15]} ; * *$ 《土壤环境质量标准》( GB15618-1995) $)^{[18]}$ 中 II 级标准

图 2 为研究区域水稻土重金属元素含量的频数分布图。从图中可以看出, $\mathrm{Cd} 、 \mathrm{Hg}$ 和 $\mathrm{Ni}$ 属于偏态分布, $\mathrm{Cu} 、 \mathrm{~Pb} 、 \mathrm{Cr}$ 和 $\mathrm{As}$ 属 于正态分布。研究区域水稻土重金属平均值与成都平原水稻土背景值对比分析表明, $\mathrm{Cd} 、 \mathrm{Cu} 、 \mathrm{~Pb} 、 \mathrm{Cr} 、 \mathrm{Hg} 、 \mathrm{As}$ 和 $\mathrm{Ni}$ 平均值都超过 背景值, 表明这 7 种重金属元素在成都平原水稻土上都有一定程度的累积,其中 $\mathrm{Cd}$ 为背景值的 4.12 倍, $\mathrm{Cu}$ 为 1.21 倍, $\mathrm{Pb}$ 为 1.36 倍, $\mathrm{Cr}$ 为 1.17 倍, $\mathrm{Hg}$ 为 1.05 倍, $\mathrm{As}$ 为 1.13 倍, $\mathrm{Ni}$ 为 1.18 倍, 这与贾琳等 ${ }^{[19]}$ 和解文艳等 ${ }^{[20]}$ 的研究结果相似, 表明人类活动 已经导致研究区域水稻土 $\mathrm{Cd} 、 \mathrm{Cu} 、 \mathrm{~Pb} 、 \mathrm{Cr} 、 \mathrm{Hg} 、 \mathrm{As}$ 和 $\mathrm{Ni}$ 含量的升高。 $\mathrm{Cd}$ 的累积效应最大, 这可能与研究区域北部山区为四川的 主要磷矿产区相关, 磷矿矿渣中的 Cd 随地表水而排人研究区域的主要河流如绵远河等,继而造成下流污灌区耕地土壤中 Cd 的累积; $\mathrm{Hg}$ 的累积效应最小。

区域重金属元素含量变异系数可以反映元素在该区域分布和污染程度的差异,变异系数越大,说明区域各采样点在总体样 本中平均变异程度越大 ${ }^{[21]}$ 。从表 1 可以看出, 研究区域水稻土 7 种重金属元素变异系数由大到小依次为 $\mathrm{Cd} 、 \mathrm{Hg} 、 \mathrm{Cu} 、 \mathrm{As} 、 \mathrm{Ni}$ 、 $\mathrm{Cr} 、 \mathrm{~Pb}$ 。变异系数大于 $30 \%$ 的元素有 $\mathrm{Cd} 、 \mathrm{Hg} 、 \mathrm{Cu} 、 \mathrm{As}$, 其中 $\mathrm{Cd}$ 的变异系数达到 $49.03 \%$,这说明研究区域水稻土 $\mathrm{Cd}$ 的分布差异较 大。 $\mathrm{Hg} 、 \mathrm{Cu} 、 \mathrm{As}$ 变异系数都介于 $30 \%-40 \%$ 间,存在污染程度相似性。 $\mathrm{Ni} 、 \mathrm{Cr} 、 \mathrm{~Pb}$ 变异系数都在 $20 \%$ 左右, 且非常接近, 变异系 数相对较小,空间分布相对均匀。 

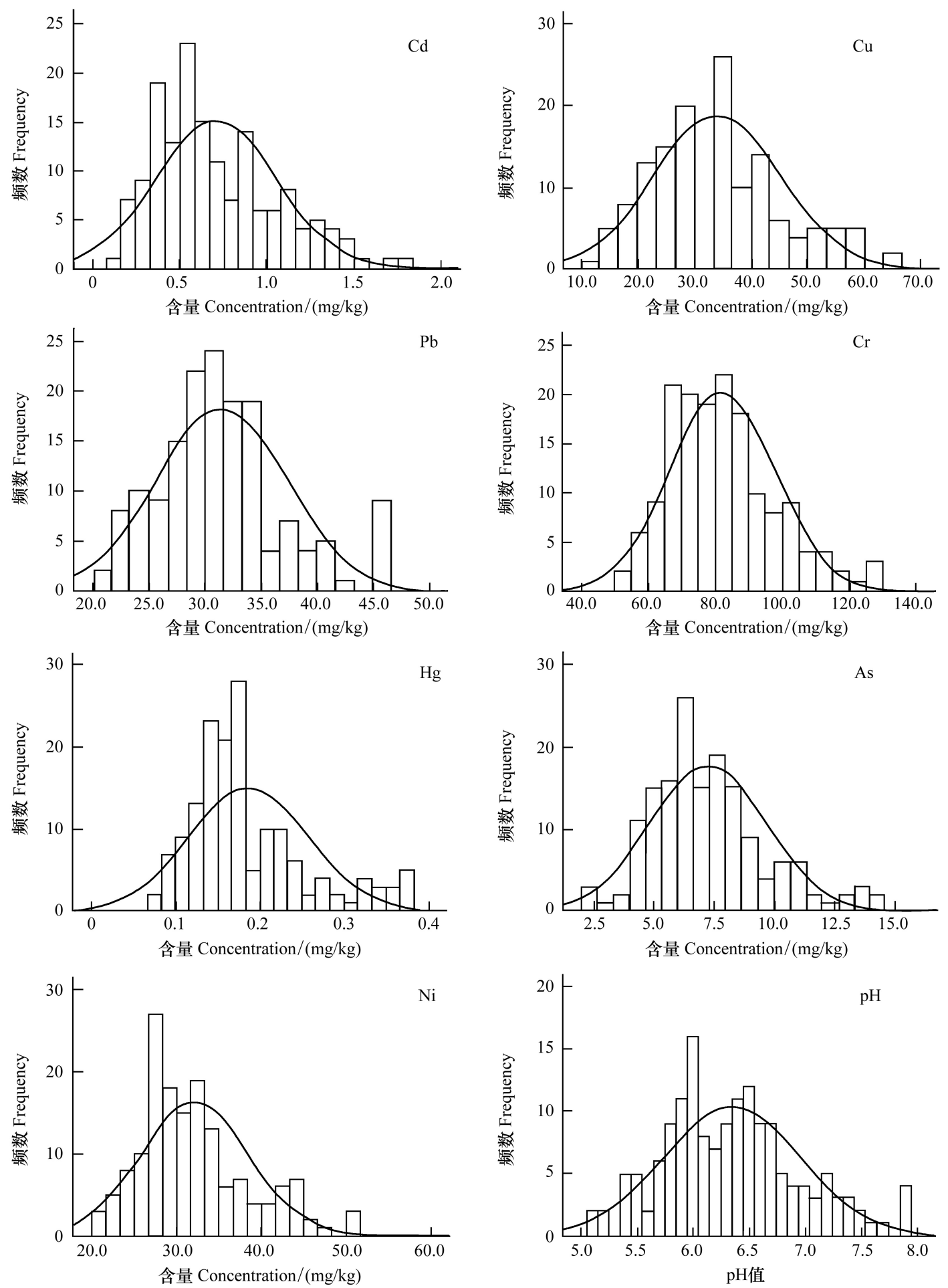

图 2 土壤重金属元素 $\mathrm{Cd} 、 \mathrm{Cu} 、 \mathrm{~Pb} 、 \mathrm{Cr} 、 \mathrm{Hg} 、 \mathrm{As} 、 \mathrm{Ni}$ 含量和 $\mathrm{pH}$ 值频数分布

Fig.2 Frequency histograms of heavy metal concentrations and $\mathrm{pH}$ of the soils

2.2 水稻土重金属元素相关性分析

同一区域内相同类型土壤重金属污染物的来源途径可以是相同的,也可以是多途径的,而同一来源的土壤重金属元素之间 通常存在一定的相关性,重金属元素间相关性显著和极显著说明元素间一般具有同源关系或者存在复合污染 ${ }^{[22] 。 P e r s o n ~}$ 相关 分析结果表明 (表 2), 成都平原水稻土多数重金属元素间存在相关性。 $\mathrm{Cd}$ 与 $\mathrm{Cu} 、 \mathrm{Hg}$ 和 $\mathrm{Ni}$ 的相关性达极显著水平 $(P<0.01)$, 与 $\mathrm{As}$ 的相关系数为 0.162 , 相关性达显著水平 $(P<0.05)$ 。 $\mathrm{Cu}$ 与 $\mathrm{Hg} 、 \mathrm{As} 、 \mathrm{Ni}$ 的相关系数都大于 0.224 , 相关性达极显著水平 $(P<$ $0.01)$ 。 $\mathrm{Pb}$ 与 $\mathrm{Cr} 、 \mathrm{As}$ 的相关性达极显著水平 $(P<0.01)$, 与 $\mathrm{Hg} 、 \mathrm{Ni}$ 的相关性达显著水平 $(P<0.05)$ 。 $\mathrm{Cr}$ 与 $\mathrm{Ni}$ 和 $\mathrm{As}$ 与 $\mathrm{Ni}$ 的相关系 
数分别为 $0.237 、 0.344$, 相关性都达极显著水平 $(P<0.01)$ 。这表明, 研究区域水稻土 $\mathrm{Cd} 、 \mathrm{Cu}$ 和 $\mathrm{Ni}$ 的来源相似性较大, 呈现相互 伴随的复合污染现象; 而 $\mathrm{Pb} 、 \mathrm{Cr}$ 和 $\mathrm{As}$ 的来源途径也可能相同 $; \mathrm{Hg}$ 的来源有一部分与 $\mathrm{Cd} 、 \mathrm{Cu} 、 \mathrm{~Pb}$ 相似, 而与 $\mathrm{As} 、 \mathrm{Cr}$ 和 $\mathrm{Ni}$ 的来源 途径差异较大。土壤 $\mathrm{pH}$ 值与 $\mathrm{Cd} 、 \mathrm{Cu}$ 和 $\mathrm{Ni}$ 的正相关性达显著水平 $(P<0.05)$, 而与 $\mathrm{Pb} 、 \mathrm{Cr} 、 \mathrm{Hg}$ 和 $\mathrm{As}$ 的相关性不显著。通常土壤 的酸碱度被认为是影响重金属形态和活性的重要因素, 低 $\mathrm{pH}$ 值土壤能促进重金属的溶解和活化,所以在酸性条件下, 重金属 $\mathrm{Cd} 、 \mathrm{Cu}$ 和 $\mathrm{Ni}$ 具有较高的溶解性,淋失量增加, 土壤重金属含量降低; 另一方面, 土壤的酸性将提高重金属 $\mathrm{Cd} 、 \mathrm{Cu}$ 和 $\mathrm{Ni}$ 等的生物 有效性,增加地面植物对这些重金属的吸收和带走量, 虽然每季的带走量不能与重金属超富积植物相比,但长期、多季的吸收和 带走仍能降低土壤中重金属含量。然而, 随着土壤酸度的增加, 重金属在土壤中的移动性和生物有效性均显著增加, 更易被作 物吸收累积, 对人体健康的威胁更大, 因此, 在轻度重金属污染土壤中, 通过施用碱性物质来提高土壤的 $\mathrm{pH}$ 值, 降低这些重金 属的生物有效性仍然是作物安全生产的重要措施。不同的土壤类型、自然区域、土地利用类型和污染环境等条件下,土壤中的 重金属来源可能差异较大,肖思思等 ${ }^{[23]}$ 对昆山市耕地土壤中重金属的相关分析表明, $\mathrm{Hg} 、 \mathrm{~Pb} 、 \mathrm{Zn} 、 \mathrm{Cd} 、 \mathrm{Cr} 、 \mathrm{Cu}$ 元素来源可能相似; Sun 等 ${ }^{[12]}$ 对沈阳市城市土壤重金属元素的相关分析指出, 土壤中 $\mathrm{Cd} 、 \mathrm{Cu} 、 \mathrm{~Pb}$ 和 $\mathrm{Zn}$ 的来源具有相似性; 而解文艳等 ${ }^{[20]}$ 对太原市 污染区土壤重金属的相关分析认为 $\mathrm{Pb} 、 \mathrm{Zn} 、 \mathrm{Cu} 、 \mathrm{Ni} 、 \mathrm{Cr} 、 \mathrm{As}$ 和 $\mathrm{Cd}$ 都可能具有相同的来源, 因此,对土壤重金属元素污染来源的判 断应在数据分析的基础上视其环境来判断。

表 2 土壤重金属元素和 pH 值 Person 相关系数矩阵

Table 2 Correlation matrix between heavy metal elements and pH

\begin{tabular}{|c|c|c|c|c|c|c|c|c|}
\hline 项目 Item & Cd & $\mathrm{Cu}$ & $\mathrm{Pb}$ & $\mathrm{Cr}$ & $\mathrm{Hg}$ & As & $\mathrm{Ni}$ & $\mathrm{pH}$ \\
\hline $\mathrm{Cd}$ & 1.000 & & & & & & & \\
\hline $\mathrm{Cu}$ & $0.468^{* *}$ & 1.000 & & & & & & \\
\hline $\mathrm{Pb}$ & 0.083 & 0.084 & 1.000 & & & & & \\
\hline $\mathrm{Cr}$ & 0.081 & 0.001 & $0.265^{* *}$ & 1.000 & & & & \\
\hline $\mathrm{Hg}$ & $0.232 * *$ & $0.276^{* * *}$ & $0.158 *$ & 0.077 & 1.000 & & & \\
\hline As & $0.162 *$ & $0.224^{* *}$ & $0.286^{* *}$ & 0.130 & -0.002 & 1.000 & & \\
\hline $\mathrm{Ni}$ & $0.359^{* *}$ & $0.732^{* * *}$ & 0.161 * & $0.237^{* *}$ & -0.003 & $0.344^{* *}$ & 1.000 & \\
\hline $\mathrm{pH}$ & $0.679^{* *}$ & 0.291 ** & -0.060 & 0.109 & 0.126 & 0.062 & $0.179^{*}$ & 1.000 \\
\hline
\end{tabular}

$*$ 相关性在 0.05 水平上显著 (2-tailed); $* *$ 相关性在 0.01 水平上显著 (2-tailed)

2.3 水稻土重金属潜在生态风险评价

\subsection{1 水稻土重金属单项生态风险评价}

采用 Hakanson 潜在生态风险指数法评价的单项污染物风险指数统计结果列于表 $3 。 \mathrm{Cd} 、 \mathrm{Cu} 、 \mathrm{~Pb} 、 \mathrm{Cr} 、 \mathrm{Hg} 、 \mathrm{As}$ 和 $\mathrm{Ni}$ 的生态风 险指数范围分别为 $28.62-305.8 、 2.22-11.31 、 4.58-9.92 、 1.50-3.59 、 16.57-83.54 、 3.60-22.38$ 和 $3.97-9.27$ 。从单项生态风 险指数平均值来看, 7 种重金属元素从高到低的排序为 $\mathrm{Cd} 、 \mathrm{Hg} 、 \mathrm{As} 、 \mathrm{~Pb} 、 \mathrm{Cu} 、 \mathrm{Ni} 、 \mathrm{Cr}$, 其中 $\mathrm{As} 、 \mathrm{~Pb} 、 \mathrm{Cu} 、 \mathrm{Ni} 、 \mathrm{Cr}$ 这 5 种元素单项生态风 险指数平均值都小于 40 , 全部样点都处于低度生态风险等级, 对区域水稻土潜在生态风险贡献较低,基本没有影响。Cd 的生态

表 3 土壤重金属单项生态风险指数统计

Table 3 Statistical analysis of the single ecological risk index of soil heavy metals

\begin{tabular}{|c|c|c|c|c|c|c|c|c|c|}
\hline \multirow{3}{*}{$\begin{array}{c}\text { 重金属 } \\
\text { Heavy } \\
\text { metal }\end{array}$} & \multirow{3}{*}{$\begin{array}{c}\text { 最小值 } \\
\text { Minimum }\end{array}$} & \multirow{3}{*}{$\begin{array}{c}\text { 最大值 } \\
\text { Maximum }\end{array}$} & \multirow{3}{*}{$\begin{array}{c}\text { 平均值 } \\
\text { Mean }\end{array}$} & \multirow{3}{*}{$\begin{array}{c}\text { 标准差 } \\
\text { Standard } \\
\text { deviation }\end{array}$} & \multicolumn{5}{|c|}{$\begin{array}{c}\text { 样点分布频数 } \\
\text { Distribution frequency of samples }\end{array}$} \\
\hline & & & & & $E_{r}<40$ & $\begin{array}{c}40 \leqslant E_{r}< \\
80\end{array}$ & $\begin{array}{c}80 \leqslant E_{r}< \\
160\end{array}$ & $\begin{array}{c}160 \leqslant E_{r}< \\
320\end{array}$ & $E_{r} \geqslant 320$ \\
\hline & & & & & $\begin{array}{l}\text { 低度 } \\
\text { Low }\end{array}$ & $\begin{array}{c}\text { 中度 } \\
\text { Medium }\end{array}$ & $\begin{array}{l}\text { 较强 } \\
\text { Strong }\end{array}$ & $\begin{array}{c}\text { 很强 } \\
\text { Very } \\
\text { strong }\end{array}$ & $\begin{array}{c}\text { 极强 } \\
\text { Greatly } \\
\text { strong }\end{array}$ \\
\hline $\mathrm{Cd}$ & 28.62 & 305.8 & 123.7 & 60.64 & 4 & 39 & 76 & 39 & 0 \\
\hline $\mathrm{Cu}$ & 2.22 & 11.31 & 6.07 & 2.01 & 158 & 0 & 0 & 0 & 0 \\
\hline $\mathrm{Pb}$ & 4.58 & 9.92 & 6.82 & 1.25 & 158 & 0 & 0 & 0 & 0 \\
\hline $\mathrm{Cr}$ & 1.50 & 3.59 & 2.34 & 0.44 & 158 & 0 & 0 & 0 & 0 \\
\hline $\mathrm{Hg}$ & 16.57 & 83.54 & 41.29 & 15.52 & 99 & 54 & 5 & 0 & 0 \\
\hline As & 3.60 & 22.38 & 11.30 & 3.73 & 158 & 0 & 0 & 0 & 0 \\
\hline $\mathrm{Ni}$ & 3.92 & 9.27 & 5.88 & 1.18 & 158 & 0 & 0 & 0 & 0 \\
\hline
\end{tabular}


风险指数最高, 只有 4 个样本处于低度生态风险等级,仅占 $2.53 \%$; 总样本中 $48.10 \%$ 的样本达到较强生态风险等级; 中度、很强 生态风险等级的分布比例相同, 各占 $24.68 \%$, 总体上生态风险程度呈恶化趋势。 $\mathrm{Hg}$ 元素样本中, 低生态风险等级样本数量占 主体地位, 其比例为 $62.66 \%$; 总样本中 $34.18 \%$ 的样本处于中度生态风险等级; 其余 $3.16 \%$ 的样本达到较强生态风险等级。 $\mathrm{Cd}$ 和 $\mathrm{Hg}$ 对区域水稻土潜在生态风险贡献率分别为 $62.27 \%$ 和 $20.78 \%$, 这表明 $\mathrm{Cd}$ 是该区域水稻土潜在生态风险的主导因子,一半 以上的生态危害都是由其造成的。

\subsection{2 水稻土重金属区域潜在生态风险评价}

研究区域水稻土 $\mathrm{Cd} 、 \mathrm{Cu} 、 \mathrm{~Pb} 、 \mathrm{Cr} 、 \mathrm{Hg} 、 \mathrm{As}$ 和 $\mathrm{Ni}$ 的综合潜在生态风险指数 $(R I)$ 最小值为 84.87 , 最大值为 398.56 , 平均值为 198.65 , 区域整体达到中度潜在生态风险等级。从不同潜在生态风险等级频数分步来看 (表 4), 大部分样本都达到中度及其以 上等级的潜在生态风险等级,其中, $66.46 \%$ 的样本处于中度潜在生态风险, $8.86 \%$ 的样本达到较强潜在生态风险, 仅 $24.68 \%$ 的 样本处于低度潜在生态风险。这表明研究区域水稻土已经存在较为严重的潜在生态风险,应引起相关部门的充分重视。张菊 等 ${ }^{[17]}$ 和宁晓波等 ${ }^{[24]}$ 研究指出单因子指数法、综合指数法和潜在生态危害指数法的评价结果具有较好的一致性, 在本研究结果 中, Hakanson 潜在生态危害指数法的评价结果显示研究区域水稻土受到 $\mathrm{Cd}$ 和 $\mathrm{Hg}$ 的生态危害, 而采用内梅罗指数法的评价结 果显示研究区域水稻土受到 $\mathrm{Cd} 、 \mathrm{Ni} 、 \mathrm{Cu}$ 和 $\mathrm{Hg}$ 的污染, 这种不一致性主要与两种评价方法的标准不一样有关; 另一方面, $\mathrm{Cd} 、 \mathrm{Ni} 、$ $\mathrm{Cu}$ 和 $\mathrm{Hg}$ 的毒性系数差异应是导致这两种方法评价结果略有差异的主要原因。任华丽等 ${ }^{[25]}$ 就指出 Hakanson 法在土壤重金属 的生态风险评价中,元素的价态效应、环境条件不同所造成的生物效应差异和评价角度不同对重金属元素毒性系数确定的差异 等都将影响重金属的评价结果, 是重金属评价应用中要重点考虑和解决的问题。

表 4 区域土壤重金属潜在生态风险指数统计

Table 4 Statistical analysis of the potential ecological risk index of soil heavy metals

\begin{tabular}{|c|c|c|c|c|}
\hline $\begin{array}{l}\text { 潜在生态风险等级 } \\
\text { Potential ecological risk degree }\end{array}$ & $R I<150$ & $150 \leqslant R I<300$ & $300 \leqslant R I<600$ & $R I \geqslant 600$ \\
\hline 程度 Degree & 低度 & 中度 & 较强 & 很强 \\
\hline 频数 Frequency & 39 & 105 & 14 & 0 \\
\hline 比例 Percentage & 24.68 & 66.46 & 8.86 & 0.00 \\
\hline
\end{tabular}

\subsection{3 水稻土生态风险因子空间分布与概率图}

为了直观、准确了解研究区域主要生态风险因子 $\mathrm{Cd}$ 和 $\mathrm{Hg}$ 的空间分布情况, 对这两个元素的单项生态风险指数进行插值, 结果见图 3。从中可以看出, 土壤 $\mathrm{Cd}$ 元素生态风险指数较高, 分布复杂, 没有 $\mathrm{Cd}$ 低度生态风险指数等级的成片分布; $\mathrm{Cd}$ 中度 生态风险指数等级分布较为零散, 主要在玉泉、什地两镇有大面积成片分布; $\mathrm{Cd}$ 很强生态风险指数等级分布范围较广, 主要分
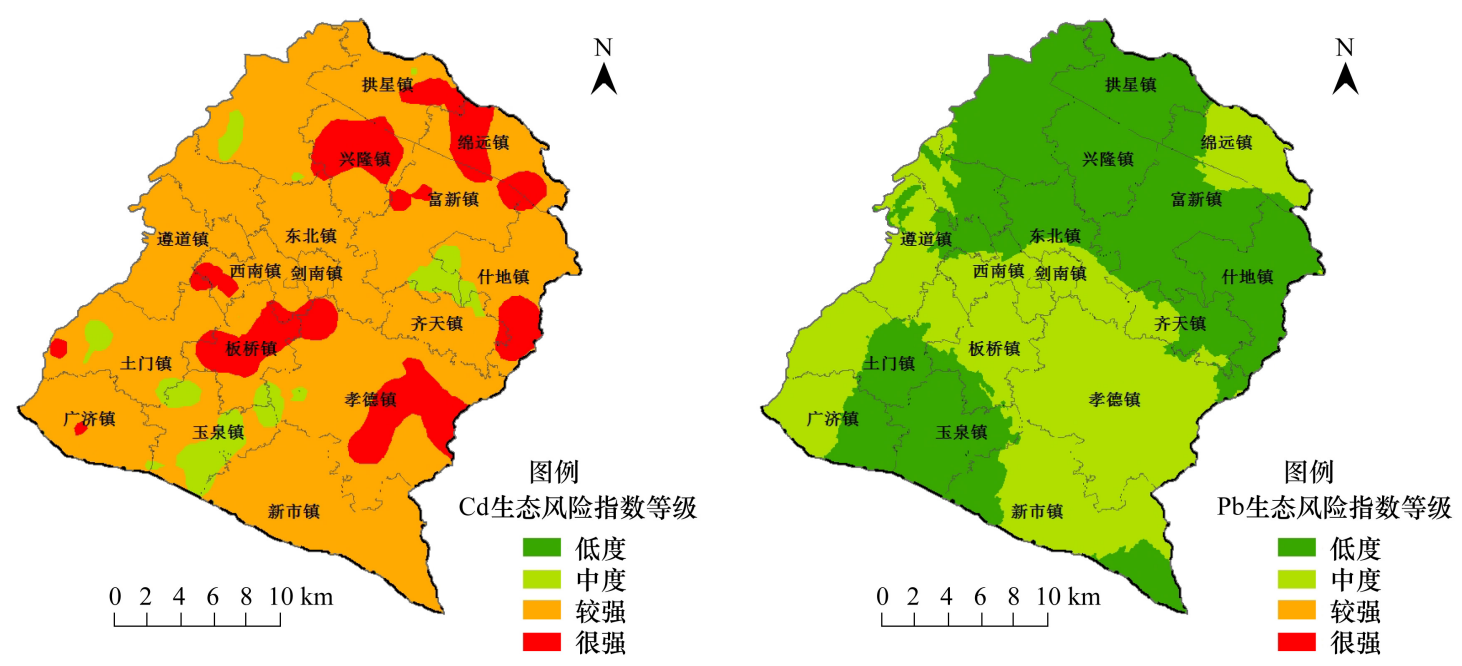

图 3 土壤 $\mathbf{C d} 、 \mathrm{Hg}$ 生态风险指数 $\left(E_{r}\right)$ 等级空间分布

Fig.3 Spatial distribution of the ecological risk index of $\mathrm{Cd}$ and $\mathrm{Hg}$ in soils 
布在研究区域东北部; $\mathrm{Cd}$ 较强生态风险指数等级在所有乡镇都有大面积分布。从 $\mathrm{Hg}$ 的生态风险指数等级分布来看,主要有低 度和中度两个等级的分布, $\mathrm{Hg}$ 低度生态风险指数等级主要分布在研究区域北部和西南部, 而 $\mathrm{Hg}$ 中度生态风险指数等级主要分 布在城区周边及南部,西北部沿龙门山区有带状分布。

风险概率分布图可以说明不同区域超过风险阈值概率的大小。根据 Hakanson 生态风险指数分级标准,40 和 80 为单因子 重金属污染物生态风险低度和中度等级的临界值,在 GIS 中采用指示克里格法, 分别以这两个值为阈值对 $\mathrm{Cd}$ 和 $\mathrm{Hg}$ 元素的生 态风险指数进行插值, 结果见图 4 。Cd 生态风险概率整体较高, 以低度指数为阈值 $(40)$, 研究区域的概率都超过 0.75 ; 以中度 指数为阈值 $(80)$, 绝大部分研究区域的 $\mathrm{Cd}$ 中度生态风险概率都超过 0.50 , 其中概率大于 0.75 的区域主要分布在城区周边、东 部和东南部, 概率低于 0.50 的区域仅在玉泉有小面积分布。 $\mathrm{Hg}$ 的生态风险概率较 $\mathrm{Cd}$ 低, 在低度指数阈值下 $(40), \mathrm{Hg}$ 低度生 态风险概率大于 0.50 的区域主要分布在城区周边及南部区域; 以中度指数为阈值 $(80), \mathrm{Hg}$ 中度生态风险概率大于 0.50 的区域 分布呈斑点状,主要分布在孝德以及孝德与玉泉结合部,面积较小, 总体概率不大。
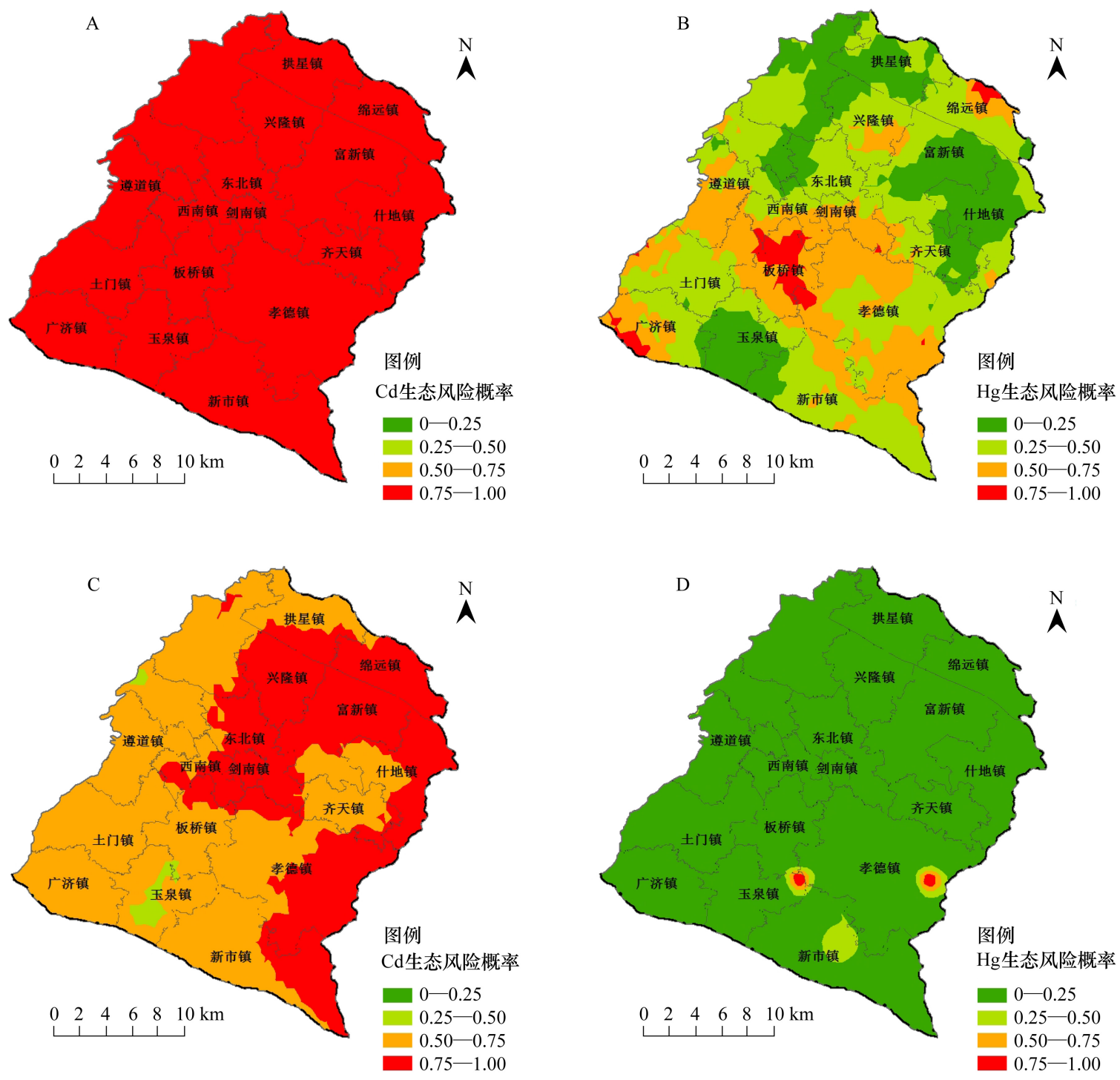

图 4 土壤 $\mathrm{Cd} 、 \mathrm{Hg}$ 生态风险指数高于 40 和 80 的风险概率图

Fig.4 Risk probability map of soil $\mathrm{Cd}$ and $\mathrm{Hg}$ with ecological risk index $>40$ and 80

( $\mathrm{A}$ 和 $\mathrm{B}$ 分别为 $\mathrm{Cd}$ 和 $\mathrm{Hg}$ 生态风险指数高于 40 风险概率图, $\mathrm{C}$ 和 $\mathrm{D}$ 分别为 $\mathrm{Cd}$ 和 $\mathrm{Hg}$ 生态风险指数高于 80 风险概率图)

潜在生态风险指数 Kriging 插值图见图 5。研究区域潜在生态风险指数等级分布以中度等级面积最大,在所有乡镇都有分 布, 占据 $90 \%$ 以上区域。潜在生态风险低度等级面积较小,分布在 3 块,包括玉泉镇大部,什地、富新和齐天镇结合部以及拱星、 汉旺北部相邻区。较强区域潜在生态风险等级仅在孝德镇的北部有一小斑块分布,在 3 种类型中面积最小。潜在生态风险指 数低度阈值风险概率图见图 6。从图中可以看到, 潜在生态风险达到中度水平的概率整体较高, 绝大部分研究区域的风险概率 
都超过 0.50 。与 $\mathrm{Cd}$ 和 $\mathrm{Hg}$ 单重金属污染风险概率图对比发现, 区域潜在生态风险中度风险概率与 $\mathrm{Cd}$ 中度阈值风险概率图空 间分布基本一致,这也说明 $\mathrm{Cd}$ 是研究区域重金属元素中潜在生态风险最大的元素,其对区域水稻土重金属潜在生态风险贡献 尤其突出。图 6 还可以看出, 区域潜在生态风险中度等级概率大于 0.75 的区域主要分布在城区周边、东部和东南部, 呈条带 状; 概率低于 0.50 的区域分布在玉泉镇及其周边, 北部龙门山带沿线有零星分布。

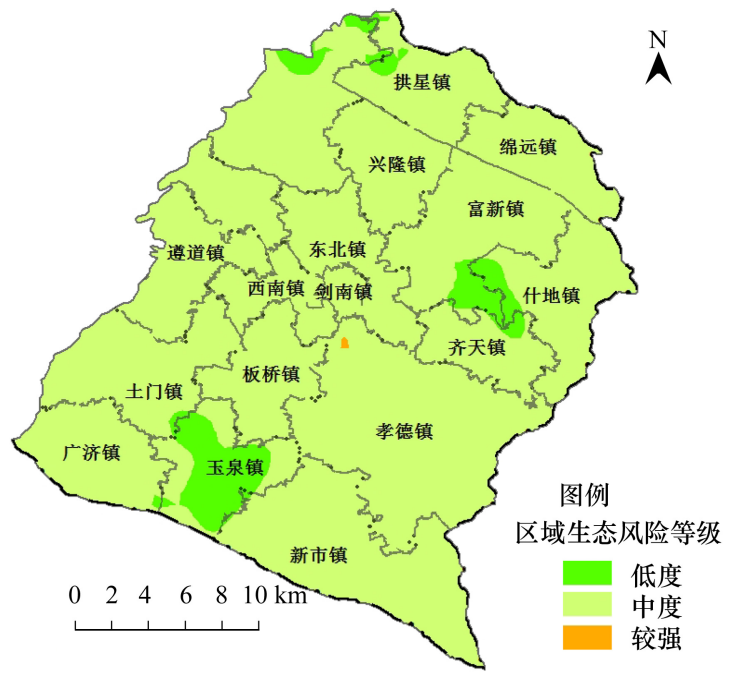

图 5 土壤区域潜在生态风险指数 $(R I)$ 等级空间分布

Fig.5 Spatial distribution of regional potential ecological risk of the soil

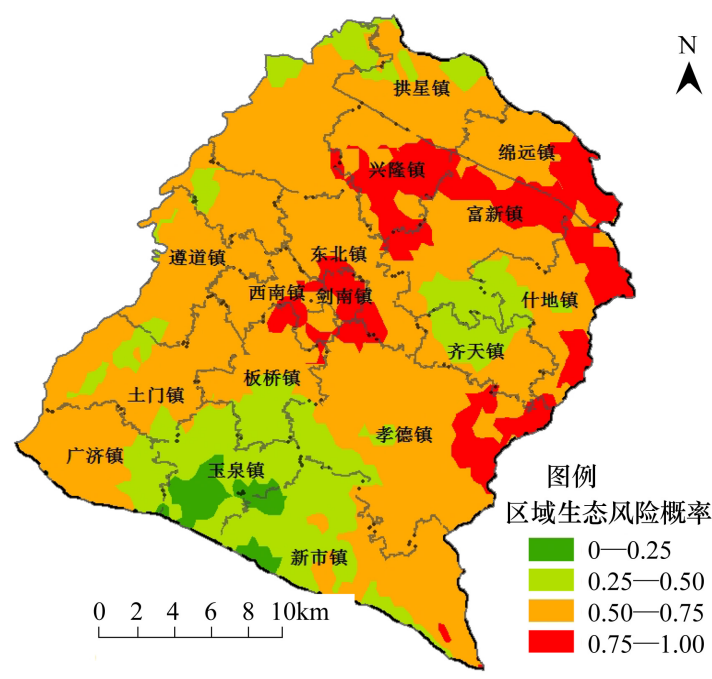

图 6 土壤区域潜在生态风险指数高于 150 风险概率图

Fig.6 Risk probability map of $R I>150$

\section{3 结论}

通过对成都平原北部区域水稻土 $\mathrm{Cd} 、 \mathrm{Cu} 、 \mathrm{~Pb} 、 \mathrm{Cr} 、 \mathrm{Hg} 、 \mathrm{As}$ 和 $\mathrm{Ni} 7$ 种重金属元素含量的统计分析和对土壤重金属污染状况和 潜在生态风险的评价, 得出以下结论:

(1) 研究区域水稻土 $\mathrm{Cd} 、 \mathrm{Cu} 、 \mathrm{~Pb} 、 \mathrm{Cr} 、 \mathrm{Hg} 、 \mathrm{As}$ 和 $\mathrm{Ni}$ 平均含量都超过背景值,呈现不同程度的积累, $\mathrm{Cd}$ 超过背景值 $312.2 \%$, 其 余元素超过背景值 5.0\%-36.5\%, Cd 积累最明显, $\mathrm{Hg}$ 积累最不明显。 $\mathrm{Cd}$ 平均含量超过土壤环境质量二级标准,其余元素平均 含量都低于土壤环境质量二级标准,特别是 $\mathrm{Pb} 、 \mathrm{Cr}$ 和 $\mathrm{As}$ 与土壤环境质量二级标准相距较远。

(2) 研究区域水稻土重金属变异差别较大, $\mathrm{Cd}$ 的变异最大,变异系数接近 $50.0 \%$; $\mathrm{Hg} 、 \mathrm{Cu} 、 \mathrm{As}$ 变异系数介于 $30 \%-40 \%$, 属 中度变异; $\mathrm{Ni} 、 \mathrm{Cr} 、 \mathrm{~Pb}$ 变异系数约为 $20.0 \%$, 变异较小。 $\mathrm{Cd} 、 \mathrm{Hg}$ 和 $\mathrm{Ni}$ 呈对数正态分布, $\mathrm{Cu} 、 \mathrm{~Pb} 、 \mathrm{Cr}$ 和 $\mathrm{As}$ 属正态分布。外界人为活 动对研究区域水稻土 $\mathrm{Cd}$ 的影响非常大, 而对 $\mathrm{Ni} 、 \mathrm{Cr} 、 \mathrm{~Pb}$ 和 $\mathrm{As}$ 的影响较小, $\mathrm{Cu}$ 和 $\mathrm{Hg}$ 受到一定的影响。

(3) 水稻土重金属元素的相关分析结果表明: $\mathrm{Cd} 、 \mathrm{Cu} 、 \mathrm{Hg}$ 和 $\mathrm{Ni}$ 元素间以及 $\mathrm{Pb} 、 \mathrm{Cr}$ 和 $\mathrm{As}$ 间都具有极显著的相关性,表现为 相互伴随的复合污染现象。7 种重金属元素来源分 3 类: $\mathrm{Cu} 、 \mathrm{Ni}$ 和 $\mathrm{Cd}$ 的来源相同,受人为影响较多,主要来源于工业污染; $\mathrm{Pb}$ 、 $\mathrm{Cr}$ 和 As 的主要来源于成土母质; $\mathrm{Hg}$ 受到人为和自然双重的影响, 可能来源于地质和工、农业活动。

(4) 水稻土整体表现为中等潜在生态风险等级,超过约 70.0\%的样本达到中度或较强潜在生态风险。Cd 是研究区域水稻 土潜在生态风险的主导因子, 其贡献率为 $62.27 \%$; 其次为 $\mathrm{Hg}$, 对区域水稻土潜在生态风险贡献率为 $20.78 \% ; \mathrm{As} 、 \mathrm{~Pb} 、 \mathrm{Cu} 、 \mathrm{Ni} 、 \mathrm{Cr}$ 都处于低生态风险等级, 对区域水稻土潜在生态风险贡献很少。从重金属潜在生态风险的概率分布特征来看,城区周边及绵远 河中、下游为区域潜在生态风险的高风险区,城区周边主要为 $\mathrm{Hg}$ 元素的生态危害贡献,而绵远河中、下游主要为 $\mathrm{Cd}$ 元素的生 态危害贡献。

\section{References:}

[ 1 ] Amini M, Afyuni M, Khademi H, Abbaspour K C, Schulin R. Mapping risk of cadmium and lead contamination to human health in soils of central Iran. Science of the Total Environment, 2005, 347(1/3): 64-77.

[ 2 ] Cheng J L, Shi Z, Zhu Y W. Assessment and mapping of environmental quality in agricultural soils of Zhejiang Province, China. Journal of Environmental Sciences, 2007, 19(1): 50-54.

[ 3 ] Song Z X, Gao M, Wang L A, Wang Z F, Xie D T, Qin J C. Heavy metal concentrations in agriculture soils of the three-gorge reservoir area and their pollution evaluation-taking $\mathrm{Cu}, \mathrm{Pb}$, and $\mathrm{Zn}$ as examples. Journal of Agro-environment Science, 2008, 27 (6) : $2189-2194$.

[ 4 ] Cheng T B. Heavy Metals Pollution of Soil. Metal World, 1999, (3) : 10-11.

[ 5 ] Cheng W D, Yao H G, Wu W, Zhang G P. Heavy metal pollution and its countermeasures in soil-rice system. Review of China Agricultural Science and Technology, 2005, 7(4): 51-54

[6] Liu H Y, Xie Z R, Cheng D Y, Zhou X M, Feng X M, Guo K Y. Primary assessment of environmental quality of soils in Chengdu Area. Acta 
Scientiae Circumstantiae, 2004, 24(2): 297-303.

[ 7 ] Li B, Wang C Q, Tan T, Li H X, Yang J, Li Q Q, Yuan Q. Regional distribution and pollution evaluation of heavy metal pollution in topsoils of the Chengdu plain. Journal of Nuclear Agricultural Sciences, 2009, 23(2) : 308-315.

[ 8 ] Liu D S, Yang Z F, Xia X Q, Hou Q Y, Yu T. Geochemical characteristics and fluxes of elements in rain water and soil leaching water in the Chengdu economic region. Earth Science Frontiers, 2008, 15(5): 74-81.

[ 9 ] Wang Z J, Deng L J, Zhang S R, Xia J G, Zhao Q Y, Hu Y F. Soil classification of main hydragric anthrosols in the Chengdu plain. Chinese Journal of Soil Science, 2004, 35(3): 241-246.

[10] Jiang F F, Sun D F, Li H, Zhou L D. Risk grade assessment for farmland pollution of heavy metals in Beijing. Transactions of the Chinese Society of Agricultural Engineering, 2011, 27(8):330-337.

[11] Wang M E, Bai Y Y, Chen W P, Markert B, Peng C, Ouyang Z Y. A GIS technology based potential eco-risk assessment of metals in urban soils in Beijing, China. Environmental Pollution, 2012, 161: 235-242.

[12] Sun Y B, Zhou Q X, Xie X K, Liu R. Spatial, sources and risk assessment of heavy metal contamination of urban soils in typical regions of Shenyang, China. Journal of Hazardous Materials, 2010, 174(1/3): 455-462.

[13] Lu R K. Analytical Methods for Soil and Agro-chemistry. Beijing: Chinese Agricultural Science and Technology Press, 2000.

[14] Hakanson L. An ecological risk index for aquatic pollution control. A sedimentological approach. Water Research, 1980, 14(8): 975-1001.

[15] Yao Y S. Study on the background values of eleven chemical elements in the alluvial paddy soils and grain crops (wheat and rice) in the agricultural economic zones of the West Sichuan Plain. Journal of Sichuan Normal University: Nature Science, 1987, (S1) : 1-67.

[16] Xu Z Q, Ni S J, Tuo X G, Zhang C J. Calculation of Heavy metals' toxicity coefficient in the evaluation of potential ecological risk index. Environmental Science \& Technology, 2008, 31(2): 112-115.

[17] Zhang J, Chen S Y, Deng H G, Wu A Q, Sun W B, Chen Y Y. Heavy metal concentrations and pollution assessment of riparian soils in Shandong Province. Acta Ecologica Sinica, 2012, 32(10): 3144-3153.

[18] Environmental Quality Standard for Soil. GB15618-1995. Beijing: Standards Press of China, 1995.

[19] Jia L, Yang L S, Ouyang Z, Wang W Y, Li H R, Li Y H, Yu J P. Assessment of the potential ecological risk of heavy metals in the farmland soils in Yucheng city, Shandong province. Journal of Agro-Environment Science, 2009, 28(11): 2270-2276.

[20] Xie W Y, Fan G S, Zhou H P, Xie J F, Guan C L. Access of heavy metals pollution of the sewage irrigation region in Taiyuan, China. Journal of Agro-Environment Science, 2011, 30(8): 1553-1560.

[21] Wang M Q, Zhang M K. Concentrations and chemical associations of heavy metals in urban and suburban soils of the Hangzhou city, Zhejiang Province. Acta Scientiae Circumstantiae, 2002, 22(5): 603-608.

[22] Galley F A, Lloyd O L. Grass and surface soils as monitors of atmospheric metal pollution in central Scotland. Water, Air, and Soil Pollution, $1985,24(1): 1-18$.

[23] Xiao S S, Huang X J, Peng B Z, Pu L J, Chen Y. Analysis of heavy metal pollution and assessment of its environmental effect in developed areas-A case study in Kunshan of Suzhou city, Jiangsu province. Resources and Environment in the Yangtze Basin, 2007, 16(5) : 674-679.

[24] Ning X B, Xiang W H, Fang X, Yan W D, Deng X W. Heavy metal concentrations and pollution assessment of limestone forests in Huaxi district, Guiyang City. Acta Ecologica Sinica, 2009, 29(4) : 2169-2177.

[25] Ren H L, Cui B S, Bai J H, Dong S K, Hu B, Zhao H. Distribution of heavy metal in paddy soil of Hani Terrace core zone and assessment on its potential ecological risk. Acta Ecologica Sinica, 2008, 28(4): 1625-1634.

\section{参考文献：}

[ 3 ] 宋珍霞, 高明, 王里奥, 王子芳, 谢德体, 秦建成. 三峡库区农业土壤重金属含量特征及污染评价一以 $\mathrm{Cu} 、 \mathrm{~Pb}$ 和 $\mathrm{Zn}$ 为例. 农业环境科 学学报, 2008, 27(6): 2189-2194.

[ 4 ] 陈同斌. 重金属对土壤的污染. 金属世界, 1999, (3): 10-11.

[ 5 ] 程旺大, 姚海根, 吴伟, 张国平. 土壤-水稻体系中的重金属污染及其控制. 中国农业科技导报, 2005, 7(4): 51-54.

[ 6 ] 刘红樱, 谢志仁, 陈德友, 周雪梅, 冯小铭, 郭坤一. 成都地区土壤环境质量初步评价. 环境科学学报, 2004, 24(2) : 297-303.

[ 7 ] 李冰, 王昌全, 谭婷, 李焕秀, 杨娟, 李启权, 袁泉. 成都平原土壤重金属区域分布特征及其污染评价. 核农学报, 2009，23(2)： 308-315.

[ 8 ] 刘东盛, 杨忠芳, 夏学齐, 侯青叶, 余涛. 成都经济区天降水与下渗水元素地球化学特征及土壤元素输人输出通量. 地学前缘, 2008,15 (5) : 74-81.

[ 9 ] 王振健, 邓良基, 张世熔, 夏建国, 赵齐阳, 胡玉福. 成都平原主要水耕人为土土系的划分研究. 土壤通报, 2004, 35(3)：241-246.

[10] 姜菲菲, 孙丹峰, 李红, 周连第. 北京市农业土壤重金属污染环境风险等级评价. 农业工程学报, 2011, 27(8): 330-337.

[13］鲁如坤. 土壤农业化学分析方法. 北京: 中国农业科技出版社, 2000.

[15] 姚延伸. 川西平原农业经济自然区冲积性水稻土及粮食作物 (小麦、大米) 中十一种化学元素背景值的研究. 四川师范大学学报: 自然 科学版, $1987,(\mathrm{~S} 1): 1-67$.

[16] 徐争启, 倪师军, 度先国, 张成江. 潜在生态危害指数法评价中重金属毒性系数计算. 环境科学与技术, 2008, 31(2)：112-115.

[17] 张菊, 陈诗越, 邓焕广, 吴爱琴, 孙卫波, 陈影影. 山东省部分水岸带土壤重金属含量及污染评价. 生态学报, 2012, 32(10): 3144-3153.

[18］ 土壤环境质量标准. GB15618-1995. 北京: 中国标准出版社, 1995.

[19］贾琳, 杨林生, 欧阳竹, 王五一, 李海蓉, 李永华, 虞江萍. 典型农业区农田土壤重金属潜在生态风险评价. 农业环境科学学报, 2009, 28(11) : 2270-2276.

[20］解文艳, 勢贵盛, 周怀平, 解静芳, 关春林. 太原市污灌区土壤重金属污染现状评价. 农业环境科学学报, 2011, 30(8)：1553-1560.

[21] 王美青, 章明奎. 杭州市城郊土壤重金属含量和形态的研究. 环境科学学报, 2002, 22(5): 603-608.

[23] 肖思思, 黄贤金, 彭补拙, 兴励杰, 陈逸. 经济发达县域耕地土壤重金属污染评价及其影响因素分析一一以江苏昆山市为例. 长江流域 资源与环境, 2007, 16(5)：674-679.

[24]宁晓波，项文化，方晰，间文德，邓湘雯. 贵阳花溪区石灰土林地土壤重金属含量特征及其污染评价. 生态学报，2009，29(4)： 2169-2177.

[25]任华丽, 崔保山, 白军红, 董世鬼, 胡波, 赵慧. 哈尼梯田湿地核心区水稻土重金属分布与潜在的生态风险. 生态学报, 2008, 28(4)： $1625-1634$ 


\section{ACTA ECOLOGICA SINICA Vol.33, No.19 Oct.,2013(Semimonthly) CONTENTS}

A review of ecosystem services and research perspectives

MA Fengjiao,LIU Jintong, A. Egrinya Eneji (5963)

Sexual interference in non-human primates

YANG Bin, WANG Chengliang, JI Weihong, et al (5973)

Density-dependent effect on reproduction of rodents : a review …............. HAN Qunhua, GUO Cong, ZHANG Meiwen (5981)

Proximate and ultimate determinants of food chain length ............................ WANG Yuyu, XU Jun, LEI Guangchun (5990)

Mechanism of biological control to plant diseases using arbuscular mycorrhizal fungi

LUO Qiaoyu, WANG Xiaojuan, LI Yuanyuan, et al (5997)

Advances in effects of conservation tillage on soil organic carbon and nitrogen

XUE Jianfu, ZHAO Xin, Shadrack Batsile Dikgwatlhe, et al (6006)

Habitat selection of the pre-released giant panda in Wolong Nature Reserve

ZHANG Mingchun, HUANG Yan, LI Desheng, et al (6014)

Activity rhythm and behavioral time budgets of wild Reeves's Pheasant (Syrmaticus reevesii) using infrared camera …................

ZHAO Yuze, WANG Zhichen, XU Jiliang, et al (6021)

The energy budget of tree sparrows Passer montanus in wind different speed and duration

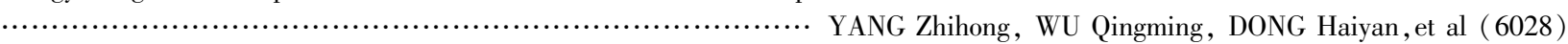

Nest site characteristics of Petaurista caniceps in Baima Snow Mountain Nature Reserve

LI Yanhong, GUAN Jinke, LI Dayong, HU Jie (6035)

Effects of habitat fragmentation on the genetic diversity of Pachycondyla luteipes on islands in the Thousand Island Lake, East

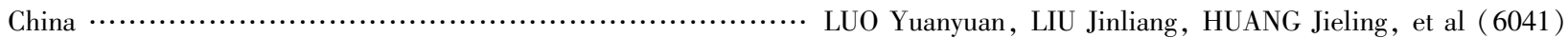

The molecular genetic relationship between the pollinators of Ficus pumila var. pumila and Ficus pumila var. awkeotsang ..............

WU Wenshan, CHEN Youling, SUN Lingli, et al (6049)

The genetic evolutionary relationships of two Eupristina species on Ficus altissima

............................................................ CHEN Youling, SUN Lingli, WU Leilei, et al (6058)

Metal uptake and root morphological changes for two varieties of Salix integra under cadmium stress

WANG Shufeng, SHI Xiang, SUN Haijing, et al (6065)

Effects of phthalic acid on seed germination, membrane lipid peroxidation and osmoregulation substance of radish seedlings ......................................................... YANG Yanjie, WANG Xiaowei, ZHAO Kang, et al (6074)

The morphological and physiological responses of Tamarix ramosissima seedling to different irrigation methods in the extremely arid area

MA Xiaodong, WANG Minghui, LI Weihong, et al (6081)

Response characteristics of photosynthetic and physiological parameters in Ziziphus jujuba var. spinosus seedling leaves to soil

water in sand habitat formed from seashells …................. WANG Rongrong, XIA Jiangbao, YANG Jihua, et al (6088)

Effects of ceramsite mulching on soil water content, photosynthetic physiological characteristics and growth of plants …...............

TAN Xuehong, GUO Xiaoping, ZHAO Tingning (6097)

Dynamics of tannin concentration and nutrient resorption for branchlets of Casuarina equisetifolia plantations at different ages .........

YE Gongfu, ZHANG Shangju, ZHANG Lihua, et al (6107)

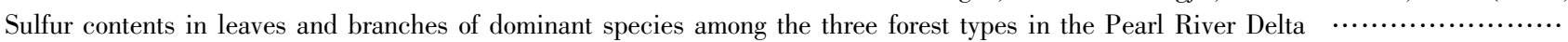

PEI Nancai, CHEN Bufeng, ZOU Zhijin, et al (6114)

Impacts of arbuscular mycorrhizal fungi and phosphorus on growth dynamics of Bauhinia faberi seedlings

SONG Chengjun, QU Laiye, MA Keming, et al (6121)

Characteristics of ion accumulation and seed germination for seeds from plants cultured at different concentrations of nitrate nitrogen and salinity

ZHOU Jiachao, FU Tingting, ZHAO Weiwei, et al (6129)

Physio-ecological effects of endophyte infection on the host grass with elevated $\mathrm{CO}_{2}$

Effects of pretreatment on germination of Typha domingensis and Phragmites australis

SHI Zhibing, ZHOU Yong, LI Xia, et al (6135)

MENG Huan, WANG Xuehong, TONG Shouzheng, et al (6142)

Transfer characteristics of cadmium from soil to Salix $\times$ aureo-pendula ….. ZHANG Wen, WEI Hong, SUN Xiaocan, et al (6147) Effect of Close-to-Nature management on the natural regeneration and species diversity in a masson pine plantation

LUO Yinghua, SUN Dongjing, LIN Jianyong, et al (6154)

Population dynamics and seed banks of the threatened seagrass Halophila beccarii in Pearl Bay, Guangxi

QIU Guanglong, FAN Hangqing, LI Zongshan, et al (6163)

Effects of biological crusts on dew deposition and evaporation in the Southern Edge of the Mu Us Sandy Land, Northern China ...... , Z

Life history characteristics and spatial distribution of Populus pruinosa population at the upper reaches of Tarim River $\cdots . . . . . . . . . . .$. .

Interactive effects of short-term nitrogen enrichment and simulated grazing on ecosystem respiration in an alpine meadow on the Tibetan Plateau ZONG Ning, SHI Peili, JIANG Jing, et al (6191) 
The correlation between soil water salinity and plant community distribution under micro-topography in Songnen Plain , W

Comparison of TSP, $\mathrm{PM}_{2.5}$ and their water-soluble ions from both inside and outside of Dafushan forest park in Guangzhou

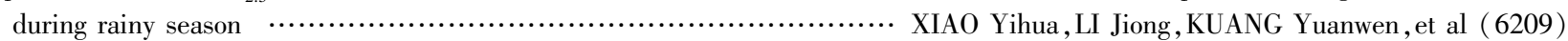

Fish community ecology in rocky reef habitat of $\mathrm{Ma}^{\prime}$ an Archipelago II . Spatio-temporal patterns of community structure

WANG Zhenhua, ZHAO Jing, WANG Kai, et al (6218)

Interannual variation in the population dynamics of snailfish Liparis tanakae in the Yellow Sea

CHEN Yunlong, SHAN Xiujuan, ZHOU Zhipeng, et al (6227)

Spatial and temporal variation of soil macro-fauna community structure in three temperate forests

... LI Na, ZHANG Xueping, ZHANG Limin (6236)

Community structure and species biodiversity of fig wasps in syconia of Ficus superba Miq. var. japonica Miq. in Fuzhou

CHEN Youling, CHEN Xiaoqian, WU Wenshan, et al (6246)

Marine ecological capital: valuation methods of marine ecosystem services …. CHEN Shang, REN Dachuan, XIA Tao, et al (6254)

Geomorphologic regionalization of China aimed at construction of nature reserve system ….......... GUO Ziliang, CUI Guofa (6264)

Impact of ecological vegetation construction on the landscape pattern of a Loess Plateau Watershed ....

YI Yang, XIN Zhongbao, QIN Yunbin, et al (6277)

Spatial heterogeneity of soil moisture across a cropland-grassland mosaic: a case study for agro-pastural transition in north of Chin

WANG Hongmei, WANG Zhongliang, WANG Kun, et al (6287)

The regional diversity of changes in growing duration of spring wheat and its correlation with climatic adaptation in Northern

China

Response of soil physical-chemical properties to rocky desertification succession in South China Karst ................................

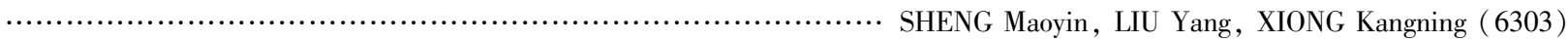

Prediction of the effects of climate change on the potential distribution of mire in Northeastern China

HE Wei, BU Rencang, LIU Hongjuan, et al (6314)

Soil nitrogen mineralization and associated temperature sensitivity of different Inner Mongolian grasslands

ZHU Jianxing, WANG Qiufeng, HE Nianpeng, et al (6320)

Effects of land use on soil nutrient in oasis-desert ecotone in the middle reach of the Heihe River

MA Zhimin, LÜ Yihe, SUN Feixiang, et al (6328)

Assessment on heavy metal pollution status in paddy soils in the northern Chengdu Plain and their potential ecological risk

QIN Yusheng, YU Hua, FENG Wenqiang, et al (6335)

Relationship between the temporal-spatial distribution of longline fishing grounds of yellowfin tuna (Thunnus albacares) and the thermocline characteristics in the Central Atlantic Ocean …......... YANG Shenglong, MA Junjie,ZHANG Yu, et al (6345)

Biological nitrogen fixation in the upper water column in the south Taiwan Strait during summer 2011

torage and drivers of forests carbon on the Beichangshan Island of Miaodao Archipelago

LIN Feng, CHEN Min, YANG Weifeng, et al (6354)

SHI Honghua, WANG Xiaoli, WANG Ai, et al (6363)

Impact of changes in vegetation types on soil $\mathrm{C}$ mineralization and associated temperature sensitivity in the Changbai Mountain

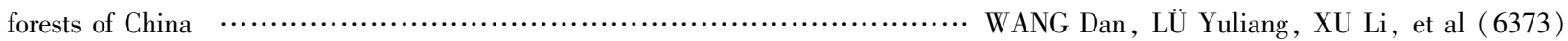

Analysis of relationship between genetic structure of Chinese Pine and mountain barriers

MENG Xiangxiang, DI Xiaoyan, WANG Mengben, et al (6382)

Soil organic carbon interpolation based on auxiliary environmental covariates:a case study at small watershed scale in Loess Hilly

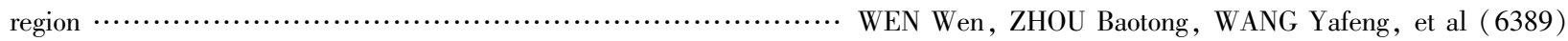

Eco-management benefit analysis of industrial resources from life cycle perspective: a case study of a virtual symbiosis network .

The game analysis between poverty and environment in ecologically fragile zones $\cdots$ QI Xinhua, YE Shilin, CHENG Yu, et al (6411)

The coupling development of economy and environment under the background of World Expo in Shanghai 


\section{《生态学报》2013 年征订启事}

《生态学报》是由中国科学技术协会主管, 中国生态学学会、中国科学院生态环境研究中心主办的生态学 高级专业学术期刊,创刊于 1981 年,报道生态学领域前沿理论和原始创新性研究成果。坚持“百花齐放,百家 争鸣” 的方针, 依靠和团结广大生态学科研工作者, 探索生态学奥秘, 为生态学基础理论研究搭建交流平台, 促进生态学研究深人发展, 为我国培养和造就生态学科研人才和知识创新服务、为国民经济建设和发展服务。

《生态学报》主要报道生态学及各分支学科的重要基础理论和应用研究的原始创新性科研成果。特别欢 迎能反映现代生态学发展方向的优秀综述性文章; 研究简报; 生态学新理论、新方法、新技术介绍; 新书评价和 学术、科研动态及开放实验室介绍等。

《生态学报》为半月刊,大 16 开本, 300 页, 国内定价 90 元/册, 全年定价 2160 元。

国内邮发代号: 82-7,国外邮发代号: M670

标准刊号:ISSN 1000-0933 CN 11-2031/Q

全国各地邮局均可订阅，也可直接与编辑部联系购买。欢迎广大科技工作者、科研单位、高等院校、图书 馆等订阅。

通讯地址: 100085 北京海淀区双清路 18 号 电话: (010)62941099; 62843362

E-mail: shengtaixuebao@ rcees.ac.cn网址: www.ecologica.cn

本期责任副主编 陈利顶 编辑部主任 孔红梅 执行编辑 刘天星 段 靖

\author{
生 态 学 报 \\ (SHENGTAI XUEBAO) \\ (半月刊 1981 年 3 月创刊)
}

第 33 卷 第 19 期 (2013 年 10 月)

\section{ACTA ECOLOGICA SINICA}

( Semimonthly, Started in 1981)

Vol. 33 No. 19 (October, 2013)

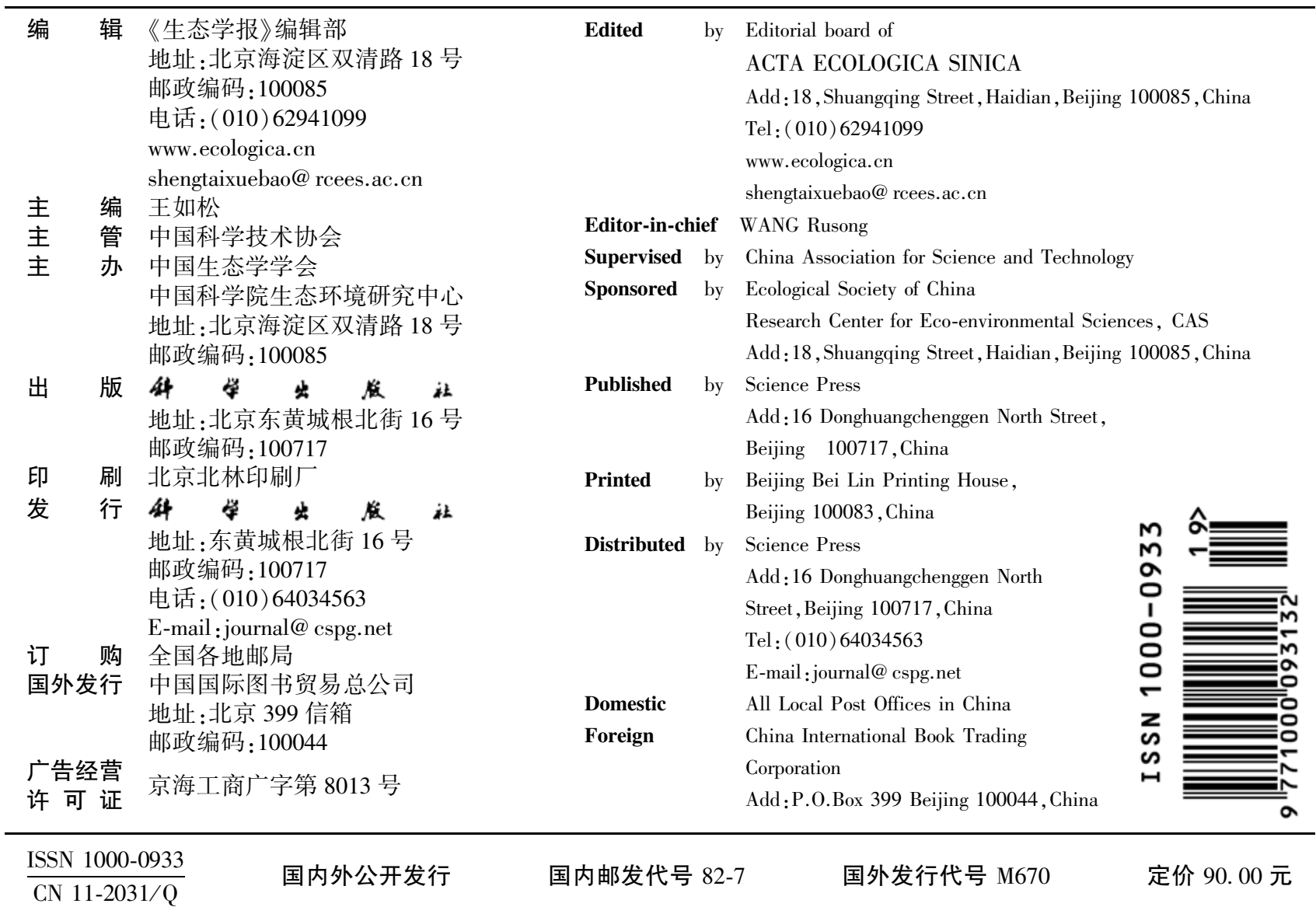

